\title{
Isolation of a target component from a multi-component mixture by coupling batch and continuous countercurrent chromatography
}

\author{
Yichu Shan ${ }^{1}$ and Andreas Seidel-Morgenstern ${ }^{1,2}$ * \\ ${ }^{1}$ Max-Planck-Institut für Dynamik komplexer technischer Systeme, Sandtorstrasse 1, D-39106 Magdeburg \\ ${ }^{2}$ Otto-von-Guericke-Universität, Universitätsplatz 2, D-39106 Magdeburg
}

\begin{abstract}
A typical situation in preparative chromatography is that a certain target component elutes somewhere in the middle of a train of other components present in the feed. In order to isolate efficiently this target component the operating conditions of conventional batch chromatography have to be optimized carefully. Nevertheless the achievable production rates and recovery yields are frequently low. Recently a possible alternative was suggested (US Patent: 6,306,306 B1, 2001 [1]) based on using batch chromatography just as a first step providing fractions where the target component has the highest or lowest retention time. Subsequently these fractions could be processed using continuous countercurrent chromatography in order to isolate the target component. Such a coupled process is analyzed theoretically for the case of linear adsorption isotherms. Based on results of simulations using a) the ideal model of chromatography and b) the equilibrium dispersive model it is demonstrated that the coupled process arrangement could possess advantages, compared to the application of batch chromatography alone.
\end{abstract}

Keyword: preparative chromatography; batch; continuous countercurrent; coupled process

*) corresponding author: seidel-morgenstern@mpi-magdeburg.mpg.de 


\section{Introduction}

The separation of a target component from multi-component mixture using preparative batch chromatography has been intensively discussed [e.g. 2-5]. It is well known that difficult separations require a careful process design and are often characterized by low throughputs and limited recovery yields [e.g. 6]. Another drawback is obviously the discontinuous character of batch chromatography. Concerning this latter aspect various types of continuously operated countercurrent chromatographic processes have been developed in order to isolate value-added products [e.g. 7-12]. Continuous processes typically allow to achieve a higher productivity and to reduce the solvent consumption [10-12]. However, they are only directly applicable for the separation of binary mixtures (e.g. enantiomers) or for the treatment of feeds where the target component to be recovered is the most or least retained component. In reality the target component is very often a component possessing an intermediate migration speed in the chromatographic process.

Based on the concept suggested recently in a patent [1], in this paper the separation of a target component from a multi-component mixture by coupling batch chromatography and continuous countercurrent chromatography is studied theoretically.

In general, the rate with which a target component can be produced using any chromatographic technique is mainly affected by the behavior of its nearest neighbors in the elution train. This fact holds in particular if the column is not extremely overloaded and the separation factors between the target component and the more remote neighbors are relatively large. Under these conditions a multi-component mixture can be considered in a simplified manner as a quasi-ternary mixture.

Below the separation of a mixture of three solutes (A, B and C) is analyzed using the ideal model of chromatography and the equilibrium dispersive model [2]. Both models are capable to describe the chromatographic process in a single batch column and in a continuously operated hypothetical true moving bed (TMB) process. The intermediate (secondly eluting) component $\mathrm{B}$ is considered to be the target component. By applying a suitable collection strategy, fractions that contain mainly only two of the solutes can be obtained from batch chromatography. Then, these fractions can be further purified by continuous countercurrent chromatography in 
order to deliver the target product with a specified purity. Below the hypothetical TMB process is considered as the second step. Although it is difficult to implement a TMB process in reality, its mathematical description is easy and it is well known, that the simulated moving bed (SMB) process, which could be realized, possesses a similar performance [7].

\section{Concepts and Theory}

\subsection{Concept}

The scheme of the considered process capable to isolate a target component $\mathrm{B}$ from a ternary mixture of A, B and C is presented in Fig. 1. It should be noted that the technique analyzed below is capable to separate a certain target component also from mixtures containing a larger number of components.

In Step 1, the multi-component (ternary) sample is injected in a batch column. It is not necessary to obtain the target component at the outlet with the required purity. Instead, it is the goal of this step to obtain two fractions (Fraction 1 and Fraction 2) containing just binary mixtures (or, if the desired purity of the target component is lower than 100\%, mixtures of two components and small amount of the third component). Due to the reduced requirements the amounts that could be injected into the batch column (e.g. the injection volumes for fixed injection concentrations) can be higher compared to the situation in which batch chromatography is applied alone. Although a direct connection between the two separation steps might be feasible it appears to be reasonable to introduce two intermediate buffer containers (Tank 1 and Tank 2) to store Fractions 1 and 2 averaging the outlet concentrations of the batch column..

In Step 2, the two fractions collected in Tanks 1 and 2 are fed to two continuously operated chromatographic countercurrent units respectively in order to obtain the purified target component $\mathrm{B}$. Due to the use of the intermediate tanks the feeds can be provided with constant concentrations and flow rates. The latter are of course limited by the supply of the batch column. It is assumed that the volumetric flow rate in the TMB units can be adjusted so that the fractions collected from the batch column can be directly processed. 
The described scheme will be analyzed below theoretically without considering the significant increase of investment costs due to the requirement of the countercurrent units. Main goal is to evaluate if there exist potential to enhance the productivity and/or to reduce the solvent consumption. Obviously it is an attractive feature of the coupled process that there exists the possibility to increase the sample throughput due to relaxed requirements on the batch column.

\subsection{Theory}

\subsubsection{Column model}

A simple analysis of coupling batch chromatography and continuous countercurrent chromatography can be performed based on conventional models capable to describe the development of band profiles in a single chromatographic column. Frequently the mass balance of the equilibrium dispersion model can be used to describe successfully the separation process in a chromatographic column [2]:

$$
\frac{\partial \mathrm{c}_{\mathrm{i}}}{\partial \mathrm{t}}+\frac{1-\varepsilon}{\varepsilon} \cdot \frac{\partial \mathrm{q}_{\mathrm{i}}(\overline{\mathrm{c}})}{\partial \mathrm{t}}+\mathrm{u} \cdot \frac{\partial \mathrm{c}_{\mathrm{i}}}{\partial \mathrm{z}}-\mathrm{u}_{\mathrm{s}} \frac{1-\varepsilon}{\varepsilon} \cdot \frac{\partial \mathrm{q}_{\mathrm{i}}(\overline{\mathrm{c}})}{\partial \mathrm{z}}=\mathrm{D}_{\mathrm{app}, \mathrm{i}} \cdot \frac{\partial^{2} \mathrm{c}_{\mathrm{i}}}{\partial \mathrm{z}^{2}} \quad \mathrm{i}=\mathrm{A}, \mathrm{B}, \mathrm{C}
$$

In eq. $1 c_{i}$ and $q_{i}$ are the liquid and solid-phase concentrations of component $i$, $\mathrm{u}$ is the interstitial fluid velocity, $\mathrm{u}_{\mathrm{s}}$ is the solid phase velocity (which is zero for batch chromatography) and $\varepsilon$ is the total porosity of the packing. A permanent equilibrium between the two phases is assumed. An apparent dispersion coefficient, $D_{\text {app,i }}$ quantifies in a simplified manner all kinetic effects causing band broadening. Often a value averaged for all components is used. For batch chromatography it is directly related to the number of theoretical plates, $\mathrm{N}_{\mathrm{p}}$, according to:

$$
\mathrm{D}_{\text {app }}=\frac{\mathrm{uL}}{2 \mathrm{~N}_{\mathrm{P}}}
$$

If $\mathrm{D}_{\text {app }}$ is zero (or $\mathrm{N}_{\mathrm{P}}$ is infinite) eq. 1 is often called the ideal model of chromatography [2] in contrast to the nonideal model $\left(\mathrm{N}_{\mathrm{p}}\right.$ finite). To apply the model 
the adsorption isotherms $\mathrm{q}_{\mathrm{i}}\left(\mathrm{c}_{1}, \mathrm{c}_{2}, \ldots, \mathrm{c}_{\mathrm{N}}\right)$ must be known. There are various isotherm models available that can be applied [2]. Below only the simple case of linear (Henry) isotherms is considered:

$$
\mathrm{q}_{\mathrm{i}}=\mathrm{H}_{\mathrm{i}} \mathrm{C}_{\mathrm{i}} \quad \mathrm{i}=\mathrm{A}, \mathrm{B}, \mathrm{C}
$$

where the $\mathrm{H}_{\mathrm{i}}$ are the Henry constants.

A separation factor between different components can be defined as:

$\alpha_{i, j}=\frac{H_{j}}{H_{i}} \quad$ (with $\left.H_{j}>H_{i}\right)$

For linear adsorption equilibrium there are many useful analytical solutions of the standard models of chromatography available [2].

\subsubsection{TMB process}

Since detailed descriptions of the TMB process and its modeling can be found elsewhere [e.g. 7-10], only a short summary will be given here. In the TMB process the stationary and mobile phases move in opposite directions. Due to the fact that in such processes there are two inlet (feed and additional desorbent) and outlet (raffinate and extract) flows there exist four characteristic regions (zones). A simplified modeling is possible if each of the four zones is described by eq. 1. The successful operation of the unit depends essentially on the appropriate selection of proper values for the flow rates in the four zones. Thus, key design parameters are four dimensionless net mass flowrate ratios, $\mathrm{m}_{\mathrm{j}}$, defined as the ratio between liquid and solid phase velocities or flowrates [9-11]. These net mass flowrate ratios are:

$$
\mathrm{m}_{\mathrm{j}}=\frac{\varepsilon \mathrm{u}_{\mathrm{j}}}{(1-\varepsilon) \mathrm{u}_{\mathrm{s}}}, \quad \mathrm{j}=1,2,3,4 \text { (zones) }
$$

The four TMB zones are indicated in Fig. 1. There are useful criteria available to determine limiting $\mathrm{m}_{\mathrm{j}}$-values guaranteeing a complete separation under ideal conditions (i.e. for $\mathrm{D}_{\mathrm{app}, \mathrm{i}}=0$ ) [9-11]. For example to achieve a complete separation of components 1 and 2 must hold under linear conditions: 
$\mathrm{m}_{4}<\mathrm{H}_{1}, \quad \mathrm{H}_{1}<\mathrm{m}_{2}<\mathrm{m}_{3}<\mathrm{H}_{2}, \mathrm{H}_{2}<\mathrm{m}_{1}$

The boundaries of the feasible operating points compose in the $m_{2}$ - $m_{3}$-plane a triangular region allowing for complete separation.

Due to the continuous character of the TMB process essentially the steady state is of interest.

\subsubsection{Initial and boundary conditions}

To quantify batch elution and TMB processes with eq. 1 appropriate initial and boundary conditions have to be provided. As indicated above, the TMB process can be described using four columns connected in series and possessing different flowrates [7-12].

Typically not preloaded columns are considered as the initial conditions for the batch column and the two TMB units consisting each out of four zones $(1,2,3$, 4), i.e.:

$\mathrm{c}_{\mathrm{i}}(\mathrm{t}=0, \mathrm{z})=0, \quad \mathrm{q}_{\mathrm{i}}(\mathrm{t}=0, \mathrm{z})=0 \quad \mathrm{i}=\mathrm{A}, \mathrm{B}, \mathrm{C}$

Neglecting backmixing effects at the column inlet the simplified boundary conditions applied for the batch column are:

$c_{i}(t, z=0)=\left\{\begin{array}{ll}c_{i n j, i} & \text { for } t \in\left[0, t_{\text {inj }}\right] \\ 0 & \text { for } t>t_{\text {inj }}\end{array}\right\} \quad \quad i=A, B, C$

where the $c_{i n j, i}$ and $t_{i n j}$ are the concentrations and times belonging to a rectangular injection profile.

Further holds at the column outlets:

$\frac{\mathrm{dc}_{\mathrm{i}}(\mathrm{t}, \mathrm{z}=\mathrm{L})}{\mathrm{dt}}=0$ $\mathrm{i}=\mathrm{A}, \mathrm{B}, \mathrm{C}$ 
The boundary conditions of the TMB units are given by the mass balances at the nodes [9-11]. Here is given only the condition which is relevant for combining the two process steps. It relates the feed concentrations of the two countercurrent units to the average concentrations of the two batch fractions collected in tanks 1 and 2:

$\mathrm{C}_{\text {Feed,TMB1,i }}=\overline{\mathrm{c}}_{\text {Fraction1,i }}$ and $\quad \mathrm{C}_{\text {Feed,TMB2,i }}=\overline{\mathrm{c}}_{\text {Fraction 2,i }} \quad \mathrm{i}=\mathrm{A}, \mathrm{B}, \mathrm{C}$

Together with eqs. (7-10) equation (1) can be solved. For the ideal model $\left(D_{\text {app }}=0\right)$ there are analytical solutions readily available. Although also for the nonideal linear case analytical solutions can be derived, below the standard explicit finite difference method suggested by Rouchon [2, 13] was applied. To solve the system of linear equations describing the TMB process, a recursive solution was applied initially proposed by Kremser [14] and recently applied to countercurrent chromatography [15].

\subsubsection{Performance criteria}

When batch chromatography is applied alone the rate of producing the target component $\mathrm{B}$ can be defined as the amount recovered from a single injection, $\mathrm{M}_{\mathrm{B} \text {,batch, }}$, divided by the cycle time, $\Delta \mathrm{t}_{\mathrm{c}}$, and the amount (volume) of stationary phase

$$
\operatorname{Pr}_{\mathrm{B}, \text { batch }}=\frac{\mathrm{M}_{\mathrm{B}, \mathrm{batch}}}{\Delta \mathrm{t}_{\mathrm{c}}(1-\varepsilon) \mathrm{V}_{\mathrm{col}}}
$$

The cycle time, $\Delta \mathrm{t}_{\mathrm{c}}$, is the time between two consecutive injections. It can be specified by two characteristic times: a) $t_{1}^{\text {start }}$, the time when the concentration of the first eluting component A exceeds a given specified threshold concentration $\left(\mathrm{C}_{\text {threshold }}\right.$ ), and $\left.\mathrm{b}\right) \mathrm{t}_{\mathrm{N}}^{\mathrm{end}}$, the time when the concentration of the last eluting component drops below this value [6]. Thus, for $\Delta t_{c}$ holds:

$$
\Delta \mathrm{t}_{\mathrm{c}}=\mathrm{t}_{\mathrm{N}}^{\mathrm{end}}-\mathrm{t}_{1}^{\mathrm{start}}
$$


A recovery yield of component $B, Y_{B}$, can be defined as the ratio of the amount recovered over the amount injected:

$$
Y_{B, \text { batch }}=\frac{M_{B, \text { batch }}}{C_{\text {inj, B }} V_{\text {inj }}}
$$

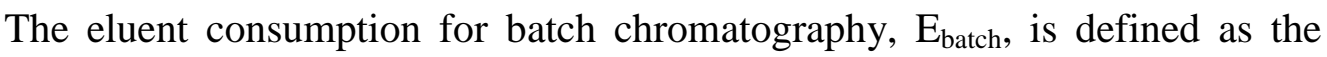
volume of the consumed eluent divided by the mass of the target component produced:

$$
\mathrm{E}_{\text {batch }}=\frac{\mathrm{Q}_{\text {batch }} \cdot \Delta \mathrm{t}_{\mathrm{c}}}{\mathrm{M}_{\mathrm{B}, \text { batch }}} \quad \text { with } \quad \mathrm{Q}_{\text {batch }}=\varepsilon \mathrm{u} \frac{\pi}{4} \mathrm{~d}_{\text {col }}^{2}
$$

where $\mathrm{Q}_{\text {batch }}$ is the volumetric flow rate in batch chromatography.

An application of the coupled process considered in Fig. 1 obviously requires significant additional investment. Thus, it appears to be only reasonable to consider this technique if the amount of sample that could be processed is much larger than in the case based solely on batch chromatography. A complete optimization of the coupled process would have to include an independent determination of suitable column sizes for the two process steps. To identify general trends, below the following simplifying assumption was applied. Each of the two TMB units was considered to consist out of 4 columns of the same size as the batch column applied. Thus in each zone of the TMB units one column was placed. Since typically smaller columns are applicable in continuous processes than in batch processes this appears to be a worst case scenario regarding an evaluation of the coupled process.

To evaluate the performance of the coupled process, the production rate can be defined as follows:

$\operatorname{Pr}_{\mathrm{B}, \text { coup }}=\operatorname{Pr}_{\mathrm{B}, \text { batch }} \frac{\mathrm{Y}_{\mathrm{B}, \mathrm{TMB}}}{9}=\frac{\mathrm{M}_{\mathrm{B}, \text { batch }}}{\Delta \mathrm{t}_{\mathrm{c}}(1-\varepsilon) \mathrm{V}_{\text {col }}} \frac{\mathrm{Y}_{\mathrm{B}, \mathrm{TMB}}}{9}$

where $\mathrm{Y}_{\mathrm{B}, \mathrm{TMB}}$ is the overall yield of the two TMB units with respect to the target component B defined as: 


$$
Y_{\text {B,TMB }}=\frac{Q_{\text {Extr,TMB1 }} C_{\text {B,Ext,TMB1 }}+Q_{\text {Raff,TMB2 }} C_{\text {B,Raff,TMB2 }}}{Q_{\text {Feed,TMB1 } 1} C_{\text {B,Feed,TMB1 }}+Q_{\text {Feed,TMB2 }} C_{\text {B,Feed,TMB2 }}}
$$

An overall yield of the coupled process can be expressed by:

$$
\mathrm{Y}_{\mathrm{B}, \text { coup }}=\frac{\mathrm{M}_{\mathrm{B}, \text { batch }}}{\mathrm{V}_{\mathrm{inj}} \mathrm{C}_{\mathrm{inj}, \mathrm{B}}} \mathrm{Y}_{\mathrm{B}, \mathrm{TMB}}
$$

The specific overall eluent consumption is the sum of the solvent used by batch chromatography and the solvent supplied to the two continuous countercurrent units divided by the total mass of produced target:

$$
\mathrm{E}_{\text {coup }}=\frac{\Delta \mathrm{t}_{\mathrm{c}} \cdot\left(\mathrm{Q}_{\text {batch }}+\mathrm{Q}_{\mathrm{D}, \mathrm{TMB} 1}+\mathrm{Q}_{\mathrm{D}, \mathrm{TMB} 2}\right)}{\mathrm{M}_{\mathrm{B}, \text { batch }} \cdot \mathrm{Y}_{\mathrm{B}, \mathrm{TMB}}}
$$

where $\mathrm{Q}_{\mathrm{D}, \mathrm{TMB}}$ and $\mathrm{Q}_{\mathrm{D}, \mathrm{TMB} 2}$ are the volumetric flowrates of the desorbent streams used in TMB1 and TMB2, respectively.

\section{Results and Discussion}

In the parametric studies performed essentially one set of reference parameters was. Typical HPLC column dimensions were used. The difference between the Henry constant for components $\mathrm{A}$ and $\mathrm{B}$, and $\mathrm{B}$ and $\mathrm{C}$ were assumed to be equal $\left(\mathrm{H}_{\mathrm{B}}{ }^{-}\right.$ $\mathrm{H}_{\mathrm{A}}=\mathrm{H}_{\mathrm{C}}-\mathrm{H}_{\mathrm{B}}=0.5$ ). Further, a 1:1:1 feed mixture with constant concentration was considered. The fixed parameters for the calculations are summarized in Table 1. The following four situations were considered:

I) Ideal batch chromatography $\left(\mathrm{D}_{\mathrm{app}}=0\right)$ and $100 \%$ product purity

II) Nonideal batch chromatography $\left(\mathrm{D}_{\mathrm{app}} \neq 0\right)$ and reduced product purity

III) Ideal coupled process $\left(\mathrm{D}_{\mathrm{app}}=0\right)$ and $100 \%$ product purity

IV) Nonideal coupled process $\left(\mathrm{D}_{\mathrm{app}} \neq 0\right)$ and reduced product purity 
The essential results achieved will be summarized in the end of this chapter in Table 2.

\subsection{Batch chromatography alone (ideal case, $100 \%$ purity)}

Under ideal linear conditions elution profiles conserve the shape of the injection profiles which are frequently rectangular pulses (eq. 8). The individual components just travel with different velocities and thus get separated from each other. Typical elution profiles corresponding to a case of complete resolution are illustrated in Fig. 2a. The left sides of the bands are fixed by the adsorption equilibrium constants and do not move when the injection volume is increased. Fig. $2 \mathrm{~b}$ shows the situation when the injection volume has exactly the size to cause touching of the bands. Due to the fact that for the selected reference parameters holds $\mathrm{H}_{\mathrm{C}}-\mathrm{H}_{\mathrm{B}}=\mathrm{H}_{\mathrm{B}}-\mathrm{H}_{\mathrm{A}}$, the band of B starts to touch simultaneously the bands of A and C. If the injection volume is further increased, the band of $B$ gets contaminated by components $\mathrm{A}$ and $\mathrm{C}$ and the fraction of pure $\mathrm{B}$ decreases (Figs. 2c and 2d). The dependence of the productivity with which $\mathrm{B}$ can be obtained as a function of the injection volume can be calculated analytically. For the parameters considered the result is shown in Fig. 3. The maximum corresponds to the touching band situation shown in Fig. 2b. The corresponding optimal injection volume can be calculated with the following equation:

$$
\mathrm{V}_{\text {inj, batch }}^{\text {opt }}=\frac{L_{\text {batch }}}{\mathrm{u}} \frac{1-\varepsilon}{\varepsilon} \cdot \Delta \mathrm{H}_{\mathrm{B}} \text { with } \quad \Delta \mathrm{H}_{\mathrm{B}}= \begin{cases}\mathrm{H}_{\mathrm{B}}-\mathrm{H}_{\mathrm{A}} & \text { if } \mathrm{H}_{\mathrm{B}}-\mathrm{H}_{\mathrm{A}} \leq \mathrm{H}_{\mathrm{C}}-\mathrm{H}_{\mathrm{B}} \\ \mathrm{H}_{\mathrm{C}}-\mathrm{H}_{\mathrm{B}} & \text { if } \mathrm{H}_{\mathrm{B}}-\mathrm{H}_{\mathrm{A}}>\mathrm{H}_{\mathrm{C}}-\mathrm{H}_{\mathrm{B}}\end{cases}
$$

In the case considered for an injection volume of $1.413 \mathrm{ml}$ the bands of components A and C begin to touch and no more pure B can be collected.

More general, the optimal conditions for producing a target component with $100 \%$ purity by ideal batch chromatography alone are obtained when one peak of the nearest neighbours begins to overlap with the peak of the target component. The corresponding cycle time is:

$$
\Delta \mathrm{t}_{\mathrm{c}, \text { batch }}^{\mathrm{opt}}=\frac{\mathrm{L}}{\mathrm{u}} \cdot \frac{1-\varepsilon}{\varepsilon} \cdot\left(\mathrm{H}_{\mathrm{C}}-\mathrm{H}_{\mathrm{A}}+\Delta \mathrm{H}_{\mathrm{B}}\right)
$$


According to eqs. 11, 19 and 20, the optimal production rate is:

$$
\operatorname{Pr}_{\mathrm{B}, \text { batch }}^{\mathrm{opt}}=\frac{\mathrm{C}_{\mathrm{inj}, \mathrm{B}} \cdot \mathrm{V}_{\mathrm{inj}, \text { batch }}^{\mathrm{opt}}}{\Delta \mathrm{t}_{\mathrm{c} \text {,batch }}^{\mathrm{opt}}(1-\varepsilon) \mathrm{V}_{\mathrm{col}}}=\frac{\mathrm{C}_{\mathrm{inj}, \mathrm{B}} \cdot \mathrm{Q}_{\text {batch }}}{(1-\varepsilon) \mathrm{V}_{\text {col }}} \cdot \frac{\Delta \mathrm{H}_{\mathrm{B}}}{\mathrm{H}_{\mathrm{C}}-\mathrm{H}_{\mathrm{A}}+\Delta \mathrm{H}_{\mathrm{B}}}
$$

The corresponding solvent consumption is according to eq. 14,19 and 20 :

$$
\mathrm{E}_{\text {batch }}^{\text {opt }}=\frac{\Delta \mathrm{t}_{\mathrm{c}, \text { batch }}^{\text {opt }} \cdot \mathrm{Q}_{\text {batch }}}{\mathrm{C}_{\mathrm{inj, \textrm {B }}} \cdot \mathrm{V}_{\mathrm{inj}, \text { batch }}^{\text {opt }}}=\frac{\mathrm{H}_{\mathrm{C}}-\mathrm{H}_{\mathrm{A}}+\Delta \mathrm{H}_{\mathrm{B}}}{\mathrm{C}_{\mathrm{inj}, \mathrm{B}} \cdot \Delta \mathrm{H}_{\mathrm{B}}}
$$

For the special case considered here, the optimum injection volume is $0.707 \mathrm{~mL}$, the optimum productivity of the target component is $14.15 \mathrm{~g} \cdot \mathrm{L}^{-1} \cdot \mathrm{h}^{-1}$ and the eluent consumption is $3.000 \mathrm{~L} / \mathrm{g}$. All these values can be found as a reference state in Table 2.

\subsection{Batch chromatography alone (nonideal case, reduced purity)}

In reality the separation between different components is not only related to the isotherms but also to the column efficiency. Using the same parameter set as used above and a plate number of $\mathrm{N}_{\mathrm{P}}=1200$, the injection volume was optimized numerically in order to obtain the highest productivity for the target component B.

For a predefined requirement of purity (below $\operatorname{Pur}_{\mathrm{B}, \mathrm{des}}=99 \%$ ), the start and end times of fraction collection and thus the productivity can be determined by applying a suitable cutting strategy. In the analysis the same procedure as described in [6] was used. Fig. 4 shows elution profiles for different injection volumes and fixed injection concentrations. The determined dependence of productivity on injection volume is shown in Fig. 5. When the injection volume is small, there is a time interval during which the target component can be collected with high purity. There is no overlapping between the peaks of first and third component. The optimal injection volume can be obtained by finding the injection volume corresponding to the maximum production rate. Fig. 4a presents the optimal chromatogram for the separation of target component from ternary mixture by batch chromatography alone. When the injection 
volume becomes larger, the time interval in which the target component is sufficiently pure becomes smaller. At a certain injection volume, the peaks of the first and the last component begin to overlap with each other and the target component can not be isolated anymore (see Figure 4b). The described tendency can be seen in Fig. 5. It should be noted that the optimal injection volume for the production of target component using batch chromatography is due to the dispersion effects for the nonideal case $\left(\mathrm{N}_{\mathrm{p}}=1200\right)$ much lower than for the ideal case. It is for the nonideal case $0.173 \mathrm{~mL}$ and thus only one fourth of the ideal case. The optimum productivity in the nonideal case is also lower than in the ideal case because not only the throughput but also the recovery yield is reduced. The productivity for the nonideal case is $1.001 \mathrm{~g} \cdot \mathrm{L}^{-}$ ${ }^{1} \cdot \mathrm{h}^{-1}$ (which is much lower that for ideal case: $14.15 \mathrm{~g} \cdot \mathrm{L}^{-1} \cdot \mathrm{h}^{-1}$ ). The eluent consumption is $42.43 \mathrm{~L} / \mathrm{g}$ (which is much higher than that of ideal case, see Table 2).

\subsection{Coupled process (ideal case, $100 \%$ purity)}

If the described coupled process is applied, the volume injected in the batch column can be increased, because it is not necessary to get pure target component exclusively in this step. A certain limitation is given by the requirement that the first peak does not overlap with the third peak (this point is reached in Fig. 2d). Otherwise it is not possible to obtain two fractions containing only two components each mixture. This critical injection volume can be calculated analytically as follows:

$$
\mathrm{V}_{\text {inj, coup }}^{\text {opt }}=\frac{\mathrm{LQ}_{\text {batch }}}{\mathrm{u}} \frac{1-\varepsilon}{\varepsilon} \cdot\left(\mathrm{H}_{\mathrm{C}}-\mathrm{H}_{\mathrm{A}}\right)
$$

For the case considered here, this injection volume is $1.413 \mathrm{~mL}$ (Table 2).

A ratio of the injection volumes for the two different techniques, $\eta$, can be expressed by the following equation:

$$
\eta=\frac{\mathrm{V}_{\text {inj,coup }}^{\text {opt }}}{V_{\text {inj,batch }}^{\text {opt }}}=\frac{H_{C}-H_{A}}{\Delta H_{B}}
$$


Eq. 24 reveals the fact that the larger the difference between the values of $\mathrm{H}_{\mathrm{C}^{-}}$ $\mathrm{H}_{\mathrm{B}}$ and $\mathrm{H}_{\mathrm{B}}-\mathrm{H}_{\mathrm{A}}$, the larger the increase of throughput by the coupled process compared to batch chromatography alone. For the parameters considered here $\eta$ is equal to 2, representing due to the symmetry of the Henry constants a rather low value.

According to eqs. 20 and 23, the cycle time of batch chromatography for coupled process under optimal conditions is:

$$
\Delta \mathrm{t}_{\mathrm{c}, \text { coup }}^{\mathrm{opt}}=\frac{\mathrm{L}}{\mathrm{u}} \cdot \frac{1-\varepsilon}{\varepsilon} \cdot\left(\mathrm{H}_{\mathrm{C}}-\mathrm{H}_{\mathrm{A}}+\mathrm{H}_{\mathrm{C}}-\mathrm{H}_{\mathrm{A}}\right)=\frac{\mathrm{L}}{\mathrm{u}} \cdot \frac{1-\varepsilon}{\varepsilon} \cdot 2\left(\mathrm{H}_{\mathrm{C}}-\mathrm{H}_{\mathrm{A}}\right)
$$

Combining eqs. 15, 23 and 25, for the optimum production rate of the coupled process holds:

$$
\operatorname{Pr}_{\mathrm{B}, \text { coup }}^{\text {opt }}=\frac{\mathrm{C}_{\text {inj,B }} \cdot V_{\text {inj,coup }}^{\text {opt }}}{9 \Delta \mathrm{t}_{\mathrm{c}, \text { coup }}^{\mathrm{opt}}(1-\varepsilon) \mathrm{V}_{\mathrm{col}}}=\frac{\mathrm{C}_{\mathrm{inj}, \mathrm{B}} \cdot \mathrm{Q}_{\mathrm{batch}}}{18(1-\varepsilon) \mathrm{V}_{\text {col }}}
$$

Due to eqs. 21 and 26, the ratio of the optimal production rates of the two techniques is:

$$
\operatorname{Pr}_{i, \text { coup }}^{\text {opt }} / \operatorname{Pr}_{\mathrm{i}, \text { batch }}^{\text {opt }}=\frac{\eta}{9} \cdot \frac{\mathrm{H}_{\mathrm{C}}-\mathrm{H}_{\mathrm{A}}+\Delta \mathrm{H}_{\mathrm{Bi}}}{2 \cdot\left(\mathrm{H}_{\mathrm{C}}-\mathrm{H}_{\mathrm{A}}\right)}=\frac{\mathrm{H}_{\mathrm{C}}-\mathrm{H}_{\mathrm{A}}+\Delta \mathrm{H}_{\mathrm{B}}}{18 \cdot \Delta \mathrm{H}_{\mathrm{B}}}
$$

From the point view of production rate, under ideal conditions the coupled process is advantageous only if $\mathrm{H}_{\mathrm{C}}-\mathrm{H}_{\mathrm{A}}$ is larger than 17 times of $\Delta \mathrm{H}_{\mathrm{B}}$ (eq. 27). Otherwise, if the value of $\mathrm{H}_{C}-\mathrm{H}_{B}$ is similar to $\mathrm{H}_{B}-\mathrm{H}_{\mathrm{A}}$ (or even equal as for our parameter set), the value of $\eta$ is small and it is not advantageous to use the coupled process. For the case considered, the optimum production rate of ideal coupled process is $2.358 \mathrm{~g} \cdot \mathrm{L}^{-1} \cdot \mathrm{h}^{-1}$ (Table 2), which is one sixth of that of ideal batch chromatography $\left(14.15 \mathrm{~g} \cdot \mathrm{L}^{-1} \cdot \mathrm{h}^{-1}\right)$.

Since half part of the flow in batch column is fed to two TMB units under optimum conditions (see Fig. 2d) and the desorbent flow for ideal TMB is under 
linear conditions the same as the feed flow, the total flow of eluent consumed for coupled process is $1.5 \mathrm{Q}_{\text {batch }}$. The solvent consumption of coupled process under optimal conditions can be obtained according to eq. 18, 23 and 25:

$$
\mathrm{E}_{\text {coup }}^{\mathrm{opt}}=\frac{\Delta \mathrm{t}_{\mathrm{c}, \text { coup }}^{\mathrm{opt}} \cdot 1.5 \cdot \mathrm{Q}_{\text {batch }}}{\mathrm{C}_{\mathrm{inj}, \mathrm{B}} \cdot \mathrm{V}_{\mathrm{inj}, \text { coup }}^{\mathrm{opt}}}=\frac{3}{\mathrm{C}_{\mathrm{inj}, \mathrm{B}}}
$$

Comparing eqs. 22 and 28, it can be seen that the eluent consumption of the coupled process is equal to that of batch chromatography alone if $\mathrm{H}_{B}-\mathrm{H}_{\mathrm{A}}$ equals to $\mathrm{H}_{\mathrm{C}}-\mathrm{H}_{\mathrm{B}}$ (as considered above). Otherwise, the eluent consumption of the ideal coupled process will be smaller. The larger $\frac{\mathrm{H}_{\mathrm{C}}-\mathrm{H}_{\mathrm{A}}}{\Delta \mathrm{H}_{\mathrm{B}}}$, the larger is the difference between the eluent consumptions of two techniques.

\subsection{Coupled process (nonideal case, reduced purity)}

A more detailed view is given below to the coupled process assuming nonideal conditions. As shown in Fig. 4b, for an injection volume of $0.271 \mathrm{~mL}$ the peaks of the first and the third component begin to overlap with each other. For this injection volume, two binary mixtures (Fraction 1 and 2) can be obtained by applying suitable cutting strategy. The pure component B can be obtained by separating these binary mixtures using TMB units. If the desired purity is lower than 100\% , e.g. again 99\%, a small amount of component $\mathrm{C}$ existing in Fraction 1 and of component A existing in Fraction 2 is allowed. To distinguish between the two impurities in the fractions, the components are named below according to their amounts. Component $\mathrm{A}$ in Fraction 1 and component $\mathrm{C}$ in Fraction 2 are called “major impurity”, while component C in Fraction 1 and component A in Fraction 2 are called "minor impurity". At first we assume the worst case scenario that the target component and the major impurity can be completely separated by the TMB units and that all of the minor impurity co-elutes with the target component. 


\subsubsection{Amount of minor impurity in the collected fractions is equal to 1 -Pur ${ }_{B, d e s}$}

The method to determine the optimal injection volumes and the corresponding cut times for the batch column to achieve that the amount of the minor impurity in the collected fractions is equal to $\left(1-\right.$ Pur $\left._{\mathrm{B}, \mathrm{des}}\right)$ is as follows:

a) Apply a certain injection volume in batch column and simulate the elution profile of the sample.

b) The start time for Fraction 1 is fixed by setting a threshold concentration of the target component to be collected (e.g. $\mathrm{c}_{\text {threshold }}=0.01 \mathrm{c}_{\max }$ ). Integrate from the start time of Fraction 1 until the amount of component $C$ equals to 1-Pur ${ }_{B \text {,des }}$ (e.g. here 1\%). Thus, the appropriate end time of Fraction 1 is found.

c) Take the end time of Fraction 1 as the start time of Fraction 2, determine the end time of Fraction 2 by the threshold concentration and calculate the amount of target component $\mathrm{B}$ and component $\mathrm{A}$ by integrating the elution profile from the start time to the end time of Fraction 2.

d) If the amount of component A (minor impurity in Fraction 2) is smaller than 1-Pur $r_{B, d e s}$, increase the injection volume (otherwise decrease the injection volume) and repeat the above procedure until the amount of component $\mathrm{A}$ in Fraction 2 equals to 1-Pur ${ }_{\mathrm{B}, \mathrm{des}}$ in Fraction 2. Thus the appropriate injection volume and cutting times of two fractions are obtained. For the specified case, the maximum injection volume in batch chromatography is found to be $0.7064 \mathrm{ml}$, the cycle time is 3.156 min, the effective flow rates of Fraction 1 and Fraction 2 entering TMB 1 and TMB2 were found to be $0.2799 \mathrm{~mL} / \mathrm{min}$ and $0.2687 \mathrm{~mL} / \mathrm{min}$, respectively. The average concentrations in the two batch fractions are $C_{A}: C_{B}: C_{C}=0.5731: 0.3997: 0.0039 \mathrm{~g} / \mathrm{L}$ (Fraction 1) and $\mathrm{C}_{\mathrm{A}}: \mathrm{C}_{\mathrm{B}}: \mathrm{C}_{\mathrm{C}}=0.0040: 0.4161: 0.5743 \mathrm{~g} / \mathrm{L}$ in (Fraction 2).

For the linear ideal case, the parameter region allowing for a complete separation of the components $\mathrm{A}$ and $\mathrm{B}$ present in Fraction 1 by TMB is:

$$
\mathrm{m}_{4}<=\mathrm{H}_{\mathrm{A}}<=\mathrm{m}_{2}<\mathrm{m}_{3}<=\mathrm{H}_{\mathrm{B}}<=\mathrm{m}_{1}
$$

The plane $\mathrm{m}_{2}-\mathrm{m}_{3}$ shown in Fig. 6 for the nonideal case was determined for $\mathrm{N}_{\mathrm{P}}=1200$ by systematically simulating the internal concentration profiles using the mentioned algorithm [15]. In order to fix for the analysis of the coupled process a certain operating point, a safety factor $\beta$ was introduced rendering the inequalities into 
equations and allowing to determine a specific set of $m_{i}$ values [10]. For the study presented here a value of 1.01 was used for $\beta$ in all inequalities. The $m_{i}$ values applied for TMB1 are $\mathrm{m}_{1}: \mathrm{m}_{2}: \mathrm{m}_{3}: \mathrm{m}_{4}=4.04: 3.525: 3.970: 3.465$, respectively. The corresponding steady-state concentration profiles are shown in Fig. 7. The purity of the target component B leaving the extract port is $99.32 \%$, which is larger than the desired purity 99\%. The reason for this improved performance is the fact that only a part of the minor impurity co-elutes with the target component (see Fig. 7). This is in contrast to the assumption that all of the minor impurity co-elutes with the target component. Thus, a larger amount of minor impurity can be accepted in the collected batch fractions.

A similar approach as described above can be performed to quantify the separation of Fraction 2 by TMB2. Also there the purity of the target (here leaving the unit at the raffinate port) is larger than 99\% (Table 2).

\subsubsection{Amount of minor impurity in the collected fractions is larger than 1-Pur ${ }_{B, d e s}$}

To find a maximum acceptable amount of minor impurity in Fractions 1 and 2 (component $\mathrm{C}$ or component $\mathrm{A}$ ), it is essential to study the concentration profiles of these components in TMB1 or in TMB2. Below the discussion is focused on the situation for TMB1. The concentration profile of the minor impurity in Fraction 2 (component A) entering TMB2 can be studied in similar way. As shown already in Fig. 7, there is a two-step concentration profile of component $\mathrm{C}$ at steady state. Thus, this component behaves similar as an adsorbable constituent of the solvent. The internal concentration levels can be calculated by solving the mass balance at the desorbent node [11]:

$\mathrm{C}_{\mathrm{R}, \mathrm{C}} \cdot \mathrm{Q}_{\mathrm{s}} \cdot\left(\mathrm{m}_{4}-\mathrm{H}_{\mathrm{C}}\right)+\mathrm{C}_{\mathrm{D}, \mathrm{C}} \cdot \mathrm{Q}_{\mathrm{s}} \cdot\left(\mathrm{m}_{1}-\mathrm{m}_{2}\right)=\mathrm{C}_{\mathrm{E}, \mathrm{C}} \cdot \mathrm{Q}_{\mathrm{s}} \cdot\left(\mathrm{m}_{1}-\mathrm{H}_{\mathrm{C}}\right)$

In the above $Q_{s}$ is the flow rate of the solid phase which is equal to $(1-\varepsilon) \mathrm{u}_{\mathrm{s}} \frac{\pi}{4} \mathrm{~d}_{\text {col }}^{2}$. The $C_{R, C}, C_{D, C}$ and $C_{E, C}$ are the concentrations of component $C$ in the raffinate, desorbent and extract streams, respectively. Since there is no component $C$ in the 
desorbent it further holds:

$\frac{\mathrm{C}_{\mathrm{E}, \mathrm{C}}}{\mathrm{C}_{\mathrm{R}, \mathrm{C}}}=\frac{\mathrm{H}_{\mathrm{C}}-\mathrm{m}_{4}}{\mathrm{H}_{\mathrm{C}}-\mathrm{m}_{1}}$

For the total mass balance equation of component $\mathrm{C}$ holds:

$\mathrm{C}_{\mathrm{E}, \mathrm{C}} \cdot \mathrm{Q}_{\mathrm{s}} \cdot\left(\mathrm{m}_{1}-\mathrm{m}_{2}\right)+\mathrm{C}_{\mathrm{R}, \mathrm{C}} \cdot \mathrm{Q}_{\mathrm{s}} \cdot\left(\mathrm{m}_{3}-\mathrm{m}_{4}\right)=\mathrm{C}_{\mathrm{F}, \mathrm{C}} \cdot \mathrm{Q}_{\mathrm{s}} \cdot\left(\mathrm{m}_{3}-\mathrm{m}_{2}\right)$

Thus, the concentration of component $\mathrm{C}$ at the extract port is:

$$
\mathrm{C}_{\mathrm{E}, \mathrm{C}}=\frac{\mathrm{C}_{\mathrm{F}, \mathrm{C}} \cdot\left(\mathrm{m}_{3}-\mathrm{m}_{2}\right)}{\frac{\mathrm{H}_{\mathrm{C}}-\mathrm{m}_{1}}{\mathrm{H}_{\mathrm{C}}-\mathrm{m}_{4}} \cdot\left(\mathrm{m}_{3}-\mathrm{m}_{4}\right)+\mathrm{m}_{1}-\mathrm{m}_{2}}
$$

In addition the following equation should be fulfilled to ensure the purity of the target component

$\mathrm{C}_{\mathrm{E}, \mathrm{B}} /\left(\mathrm{C}_{\mathrm{E}, \mathrm{B}}+\mathrm{C}_{\mathrm{E}, \mathrm{C}}\right)>=$ Pur $_{\mathrm{B}, \mathrm{des}}$

where holds $\mathrm{C}_{\mathrm{E}, \mathrm{B}}=\mathrm{C}_{\mathrm{F}, \mathrm{B}} \cdot\left(\mathrm{m}_{3}-\mathrm{m}_{2}\right) /\left(\mathrm{m}_{1}-\mathrm{m}_{2}\right)$.

Finally, a $\mathrm{m}_{2}-\mathrm{m}_{3}$ line on which the purity of target component equals to Pur $_{\mathrm{B}, \mathrm{des}}$ can be obtained by combining eqs. (33) and (34):

$\mathrm{m}_{3}=\mathrm{m}_{4}+\left(\gamma_{1} * \operatorname{Pur}_{\mathrm{B}, \mathrm{des}} /\left(1-\operatorname{Pur}_{\mathrm{B}, \mathrm{des}}\right)-1\right) *\left(\mathrm{H}_{\mathrm{C}}-\mathrm{m}_{4}\right) *\left(\mathrm{~m}_{1}-\mathrm{m}_{2}\right) /\left(\mathrm{H}_{\mathrm{C}}-\mathrm{m}_{1}\right)$

where $\gamma_{1}=\frac{\mathrm{C}_{\mathrm{F}, \mathrm{C}}}{\mathrm{C}_{\mathrm{F}, \mathrm{B}}}$.

Thus, the separation region is fixed by the $\mathrm{m}_{\mathrm{i}}, \gamma_{1}$ and $\operatorname{Pur}_{\mathrm{B}, \mathrm{des}} /\left(1-\operatorname{Pur}_{\mathrm{B}, \mathrm{des}}\right)$. If $\mathrm{m}_{1}, \mathrm{~m}_{4}$ and Pur $_{B \text {.des }}$ are assumed to be $\beta \cdot H_{B}, H_{A} / \beta$ and $99 \%$, respectively, the effect of the feed concentration ratio $\gamma_{1}$ on the separation region can be calculated. The trend is illustrated in Fig. 8.

When $\gamma_{1}$ is not larger than $\left(1-\operatorname{Pur}_{\mathrm{B}, \mathrm{des}}\right) / \mathrm{Pur}_{\mathrm{B}, \mathrm{des}}$, the target component with can be obtained with the desired purity of Pur $_{\mathrm{B} \text {,des }}$ in the whole triangular region. A nonseparable region appears in the left bottom corner of the region when $\gamma_{1}$ is larger than 
(1- $\left.\operatorname{Pur}_{\mathrm{B}, \mathrm{des}}\right) / \operatorname{Pur}_{\mathrm{B}, \mathrm{des}}$. This reduction of the separation region proceeds when $\gamma_{1}$ increases. From Fig. 8, it can be seen that when $\gamma_{1}$ is smaller than a certain value, the separation region of the target component includes the optimum point. The maximum permissible $\gamma_{1}$ at which desired purity of target component can be achieved at the optimum point can be obtained by substituting the values of $m_{i}$ at the optimum operating point into equation (35):

$$
\gamma_{1}^{\max }=\frac{1-\operatorname{Pur}_{\mathrm{B}, \mathrm{des}}}{\operatorname{Pur}_{\mathrm{B}, \mathrm{des}}} \times\left(1+\frac{\left(\mathrm{H}_{\mathrm{C}}-\mathrm{m}_{1}\right) \cdot\left(\mathrm{m}_{3}-\mathrm{m}_{4}\right)}{\left(\mathrm{H}_{\mathrm{C}}-\mathrm{m}_{4}\right) \cdot\left(\mathrm{m}_{1}-\mathrm{m}_{2}\right)}\right)
$$

Similarly, for the separation of Fraction 2 entering TMNB 2, a maximum $\gamma_{2}=C_{F, A} / C_{F, B}$ at which the desired purity of the target component can be achieved at the optimum point in TMB2 is:

$$
\gamma_{2}^{\max }=\frac{1-\operatorname{Pur}_{\mathrm{B}, \mathrm{des}}}{\operatorname{Pur}_{\mathrm{B}, \mathrm{des}}} \times\left(1+\frac{\left(\mathrm{m}_{4}-\mathrm{H}_{\mathrm{A}}\right) \cdot\left(\mathrm{m}_{1}-\mathrm{m}_{2}\right)}{\left(\mathrm{m}_{1}-\mathrm{H}_{\mathrm{A}}\right) \cdot\left(\mathrm{m}_{3}-\mathrm{m}_{4}\right)}\right)
$$

Substituting the concrete $m_{i}$ values used above into eqs. (36) and (37), the values of $\gamma_{1}^{\max }$ and $\gamma_{2}^{\max }$ for the specified case are 1.450 and 1.468 respectively. It can be seen that more minor impurity can be accepted from batch chromatography compared to the situation considered in the previous section. assuming directly the desired purity (1\%).

After finding the maximum tolerable amount of component $C$ in Fraction 1 and that of component $\mathrm{A}$ in Fraction 2, the maximum injection volume and the optimal cutting times in batch column can be determined applying the same method as described above. In this special case the optimal injection volume is $0.801 \mathrm{ml}$. The corresponding batch chromatogram is shown in Fig. 9. The average concentrations and effective volumetric flow rates of collected fractions are listed in Table 2. Moreover, the internal concentration profiles of each component contained in Fraction 1 (Fig. 9) in the TMB1 unit are shown in Fig. 10. It can be seen that compared to Fig. 7 there is a higher concentration level of component C. The purity of target component B eluting at extract port is equal to $99 \%\left(C_{B}: C_{C}=0.3717: 0.00382 \mathrm{~g} / \mathrm{L}\right)$. 
From Table 2 it can be seen that the optimum production rate for the coupled process is $1.163 \mathrm{~g} \cdot \mathrm{L}^{-1} \cdot \mathrm{h}^{-1}$, which is slightly higher than that of batch chromatography alone $\left(1.001 \mathrm{~g} \cdot \mathrm{L}^{-1} \cdot \mathrm{h}^{-1}\right)$. The corresponding eluent consumption for the coupled process is $7.486 \mathrm{~L} / \mathrm{g}$, which is much lower (about one sixth) than that of batch chromatography alone (42.43 L/g).

\subsection{Illustration of influence of isotherm parameters and column efficiency on the performance of coupled process}

The increase of throughput due to applying the coupled process determines whether the coupled process is advantageous or not compared to batch chromatography alone. For the linear ideal case, the size of $\eta$ (eq. 24) is only decided by the isotherm parameters (more precisely by the value of $\left(\mathrm{H}_{\mathrm{C}}-\mathrm{H}_{\mathrm{A}}\right) / \Delta \mathrm{H}_{\mathrm{B}}$ as discussed in section 3.3). Under nonideal conditions, this value is also affected by the column efficiency. By varying the isotherm parameters and plate numbers, the optimum injection volumes in batch column for two techniques studied can be obtained according to the method described before. The variations of $\eta$ with the change of isotherm parameters and column efficiency were plotted in Fig. 11. For linear nonideal conditions the increase of optimum throughput compared to batch chromatography alone is larger than that for ideal case. This improvement becomes even larger if the plate number is smaller. For example, the value of $\eta$ increases from 2.5 to 6.5 if the plate number decreases from 2000 to 1100 (compared to the ideal case, $\eta=2$ ) if $\mathrm{H}_{\mathrm{A}}: \mathrm{H}_{\mathrm{B}}: \mathrm{H}_{\mathrm{C}}=3.5: 4: 4.5$ (i.e. the reference parameters used above). If the low yield of the target componet in batch chromatography alone and the high yield of target in coupled technique (almost 100\%) is also considered, the increase of productivity of target component by applying the coupled process is even higher.

Moreover, under nonideal conditions the difference between Henry constants of different components (or separation factors between neighbouring components) also affects the vale of $\eta$. It is found from Fig. 11 that when for example both separation factors between adjacent peaks increase (e.g. $\mathrm{H}_{\mathrm{A}}: \mathrm{H}_{\mathrm{B}}: \mathrm{H}_{\mathrm{C}}=3: 4: 5$ ), the increase of throughput due to applying the coupled process is smaller compared to the case when the separation factors between adjacent peaks are small (as in the 
considered reference example). Not that the values for $\left(\mathrm{H}_{\mathrm{C}}-\mathrm{H}_{\mathrm{A}}\right) / \Delta \mathrm{H}_{\mathrm{B}}$ are equal for these two cases. These results obtained indicate that the coupled process appears to be more advantageous and suitable for difficult separations exploiting low efficiency columns.

\section{Conclusions}

The concept of coupling batch chromatography with two TMB (or SMB) units to separate a certain target component from a multi-component mixture was analyzed theoretically. The resolution of an ternary mixture was considered as an example. To obtain insight in the process several simplifying assumptions were used. First of all linear adsorption isotherms were applied. A typical set of reference parameters was chosen to perform this study. The same column dimensions were assumed for the batch process and for the TMB units. Both ideal and nonideal models of chromatography were considered and the productivity and the eluent consumption for batch chromatography alone and for the coupled process were determined and compared.

The results indicate that for the ideal linear case, the coupled process can be beneficial regarding productivity only if the difference between the Henry constants $\mathrm{H}_{\mathrm{C}}-\mathrm{H}_{\mathrm{B}}$ is much larger than $\mathrm{H}_{\mathrm{B}}-\mathrm{H}_{\mathrm{A}}$ or vice versa. The eluent consumption of the coupled process is always lower than that of batch chromatography alone as long as the differences between $\mathrm{H}_{C}-\mathrm{H}_{B}$ and $\mathrm{H}_{B}-\mathrm{H}_{\mathrm{A}}$ are not equal (as assumed in the example case studied).

For the nonideal linear case, the increase of throughput due to applying the coupled process is larger and also the yield of the target can be higher. The productivity is only slightly larger for the coupled process than for batch chromatography alone because more stationary phase is consumed in the former case. The solvent consumption of the coupled process is much lower than that consumed by batch chromatography alone. Moreover, it is found that the coupled process is especially suitable for difficult separations using columns with low efficiency.

If shorter columns can be used in continuous countercurrent chromatography compared to batch chromatography, i.e. if the consumption of stationary phase is reduced it is possible to achieve higher productivity using the coupled process. 
Moreover, shorter columns permit to apply higher flow rates in continuous countercurrent chromatography. So it is possible to apply only one TMB unit in the coupled process by arranging the feed appropriately to separate Fraction 1 in one period of time and Fraction 2 in another period of time. Then the large instrumental costs of the coupled process can be significantly reduced. An extended study of the coupled process for more complicated nonlinear isotherms is currently underway.

\section{Acknowledgement}

The authors are grateful to M. Kaspereit, G. Ziomek, G. Gedicke and Prof. Weibing Zhang for fruitful discussions. The financial support of Schering AG (Berlin) and Fonds der Chemischen Industrie is also gratefully acknowledged. 


\section{Symbols}

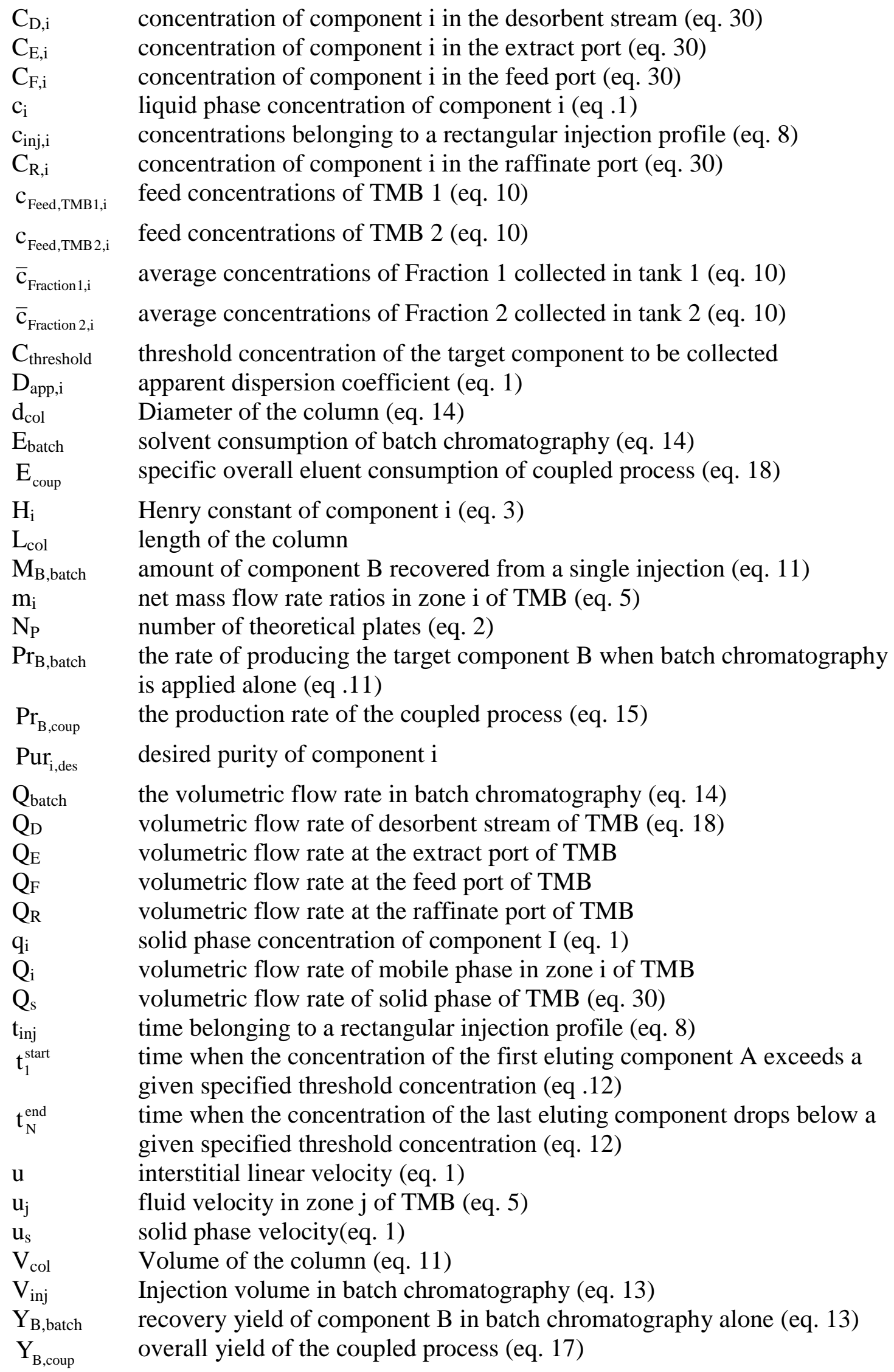


$\mathrm{Y}_{\mathrm{B}, \mathrm{TMB}} \quad$ yield of the two TMBs with respect to the target component B (eq. 15)

$\varepsilon \quad$ total porosity of the packing, (eq. 1)

$\alpha_{i, j} \quad$ separation factor between component $\mathrm{i}$ and $\mathrm{j}$ (eq. 4)

$\Delta \mathrm{t}_{\mathrm{c}} \quad$ the time between two consecutive injections (eq .11)

$\gamma_{1} \quad$ ratio of concentration of component $\mathrm{C}$ to that of component B in Fraction 1 (eq. 35)

$\gamma_{2}$ ratio of concentration of component A to that of component B in Fraction 2

$\eta \quad$ ratio of the injection volumes for the two different techniques (eq. 24) 


\section{References}

[1] U. Voigt, J. Kinkel, R. Hempel, R. Nicoud, US Patent: 6,306,306 B1 (2001)

[2] G. Guiochon, S. G. Shirazi, A. M. Katti, Fundamentals of Preparative and Nonlinear Chromatography, Academic Press, Boston, 1994.

[3] J. Haag, A. Vande Wouwer, S. Lehoucq, P. Saucez, Control Engineering Practice, 9 (2001) 921.

[4] W. Yu, K. Hidajat, A. K. Ray, Ind. Eng. Chem. Res., 42 (2003) 6743.

[5] Y. Wang, C. B. Ching, J. Chromatogr. A, 1035 (2004) 167.

[6] Y. Shan, A. Seidel-Morgenstern, J. Chromatogr. A, 1041 (2004) 53.

[7] Broughton, D. B., \& Gerhold, C. G. (1961). US Patent 2985589.

[8] D. M. Ruthven, C. B. Ching, Chem. Eng. Sci., 44(1989) 1011.

[9] M. Mazzotti, G. Storti, M. Morbidelli, AIChE J., 42 (1996) 2784.

[10] M. Mazzotti, G. Storti, M. Morbidelli, J. Chromatogr. A, 769 (1997) 3.

[11] S. Abel, M. Mazzoti, M. Morbidelli, J. Chromatogr. A, 944 (2002) 23.

[12] H. Schramm, M. Kaspereit, A. Kienle, A. Seidel-Morgenstern, J. Chromatogr. A, 1006 (2003) 77.

[13] A. Felinger, G. Guiochon J. Chromatogr. A, 658 (1994) 511.

[14] A. Kremser, National Petroleum News 22 (1930) 42.

[15] D. Beltscheva, P. Hugo, A. Seidel-Morgenstern, J. Chromatogr. A 989 (2003) 31. 
Table 1:

Parameters used in the simulations.

\begin{tabular}{|l|l|}
\hline $\begin{array}{l}\text { Column dimension and } \\
\text { porosity }\end{array}$ & $\mathrm{L}_{\mathrm{Col}}=10 \mathrm{~cm}, \mathrm{D}_{\text {col }}=6 \mathrm{~mm}, \varepsilon=0.5$ \\
\hline Column effciency & $\mathrm{N}_{\mathrm{P}}=\infty$ (ideal model) or 1200 (nonideal, eq. 1) \\
\hline Isotherm parameters & $\mathrm{H}_{\mathrm{A}}=3.5, \mathrm{H}_{\mathrm{B}}=4.0, \mathrm{H}_{\mathrm{C}}=4.5$ \\
\hline $\begin{array}{l}\text { Mobile phase flow rate } \\
\text { entering batch column }\end{array}$ & $\mathrm{Q}_{\text {batch }}=1.0 \mathrm{~mL} / \mathrm{min}$, \\
\hline $\begin{array}{l}\text { Batch column injection } \\
\text { concentrations }\end{array}$ & $\mathrm{C}_{\text {inj, } \mathrm{A}}=\mathrm{C}_{\mathrm{inj}, \mathrm{B}}=\mathrm{C}_{\mathrm{inj}, \mathrm{C}}=1 \mathrm{~g} / \mathrm{L}$ \\
\hline
\end{tabular}




\section{Table 2:}

Summary of the parametric calculations performed for four different cases.

Parameter as in Table.1

\begin{tabular}{|c|c|c|c|c|c|}
\hline & $\begin{array}{l}\text { Batch column } \\
\text { alone (ideal) }\end{array}$ & $\begin{array}{l}\text { Batch column } \\
\text { alone (nonideal) }\end{array}$ & $\begin{array}{l}\text { Coupled process } \\
\text { (ideal) }\end{array}$ & $\begin{array}{l}\text { Coupled process } \\
\text { (nonideal, } \\
\text { Chapter 3.4.1) } \\
\end{array}$ & $\begin{array}{l}\text { Coupled process } \\
\text { (nonideal, } \\
\text { Chapter 3.4.2) } \\
\end{array}$ \\
\hline Desired purity & $100 \%$ & $99 \%$ & $100 \%$ & $99 \%$ & $99 \%$ \\
\hline $\begin{array}{l}\text { Optimal injection } \\
\text { volume of batch } \\
\text { column } V_{\text {inj }} \\
\end{array}$ & $0.707 \mathrm{~mL}$ & $0.173 \mathrm{~mL}$ & $1.413 \mathrm{~mL}$ & $0.7064 \mathrm{~mL}$ & $0.801 \mathrm{~mL}$ \\
\hline $\begin{array}{l}\text { Cycle time batch } \\
\text { column } \Delta t_{c}\end{array}$ & $2.121 \mathrm{~min}$ & $2.685 \mathrm{~min}$ & $2.828 \mathrm{~min}$ & $3.156 \mathrm{~min}$ & $3.250 \mathrm{~min}$ \\
\hline Inlet of TMB1 & & & $\begin{array}{l}\mathrm{C}_{\mathrm{A}}=\mathrm{C}_{\mathrm{B}}=1.0 \mathrm{~g} / \mathrm{L} \\
\mathrm{Q}_{\mathrm{F}, \mathrm{TMB} 1}=0.25 \mathrm{~mL} / \mathrm{min} \\
\mathrm{Q}_{1, \mathrm{TMB} 1}=2.0 \mathrm{~mL} / \mathrm{min}\end{array}$ & $\begin{array}{l}\mathrm{C}_{\mathrm{A}}=0.5731 \mathrm{~g} / \mathrm{L} \\
\mathrm{C}_{\mathrm{B}}=0.3997 \mathrm{~g} / \mathrm{L} \\
\mathrm{C}_{\mathrm{C}}=0.0039 \mathrm{~g} / \mathrm{L} \\
\mathrm{Q}_{\mathrm{F}, \mathrm{TMB} 1}=0.2799 \mathrm{~mL} / \mathrm{min} \\
\mathrm{Q}_{1, \mathrm{TMB} 1}=2.411 \mathrm{~mL} / \mathrm{min}\end{array}$ & $\begin{array}{l}\mathrm{C}_{\mathrm{A}}=0.6428 \mathrm{~g} / \mathrm{L} \\
\mathrm{C}_{\mathrm{B}}=0.4301 \mathrm{~g} / \mathrm{L} \\
\mathrm{C}_{\mathrm{C}}=0.00636 \mathrm{~g} / \mathrm{L} \\
\mathrm{Q}_{\mathrm{F}, \mathrm{TMB} 1}=0.2862 \mathrm{~mL} / \mathrm{min} \\
\mathrm{Q}_{1, \mathrm{TMB} 1}=2.465 \mathrm{~mL} / \mathrm{min}\end{array}$ \\
\hline $\begin{array}{l}\text { Outlet of TMB1 } \\
\text { (Extract port) }\end{array}$ & & & $\begin{array}{l}\mathrm{C}_{\mathrm{B}}=1.0 \mathrm{~g} / \mathrm{L}, \\
\mathrm{Q}_{\mathrm{E}, \mathrm{TMB} 1}=0.25 \mathrm{~mL} / \mathrm{min}\end{array}$ & $\begin{array}{l}\mathrm{C}_{\mathrm{B}}=0.3454 \mathrm{~g} / \mathrm{L} \\
\mathrm{C}_{\mathrm{C}}=0.00235 \mathrm{~g} / \mathrm{L} \\
\mathrm{Q}_{\mathrm{E}, \mathrm{TMB} 1}=0.3239 \mathrm{~mL} / \mathrm{min}\end{array}$ & $\begin{array}{l}\mathrm{C}_{\mathrm{B}}=0.3717 \mathrm{~g} / \mathrm{L}, \\
\mathrm{C}_{\mathrm{C}}=0.00382 \mathrm{~g} / \mathrm{L}, \\
\mathrm{Q}_{\mathrm{E}, \mathrm{TMB} 1}=0.3312 \mathrm{~mL} / \mathrm{min}\end{array}$ \\
\hline $\begin{array}{l}\text { Desorbent for } \\
\text { TMB1 }\end{array}$ & & & $\mathrm{Q}_{\mathrm{D}, \mathrm{TMB} 1}=0.25 \mathrm{~mL} / \mathrm{min}$ & $\mathrm{Q}_{\mathrm{D}, \mathrm{TMB} 1}=0.3616 \mathrm{~mL} / \mathrm{min}$ & $\mathrm{Q}_{\mathrm{D}, \mathrm{TMB} 1}=0.3697 \mathrm{~mL} / \mathrm{min}$ \\
\hline Inlet of TMB2 & & & $\begin{array}{l}\mathrm{C}_{\mathrm{C}}=\mathrm{C}_{\mathrm{B}}=1.0 \mathrm{~g} / \mathrm{L} \\
\mathrm{Q}_{\mathrm{F}, \mathrm{TMB} 2}=0.25 \mathrm{~mL} / \mathrm{min} \\
\mathrm{Q}_{1, \mathrm{TMB} 2}=2.25 \mathrm{~mL} / \mathrm{min}\end{array}$ & $\begin{array}{l}\mathrm{C}_{\mathrm{A}}=0.0040 \mathrm{~g} / \mathrm{L} \\
\mathrm{C}_{\mathrm{B}}=0.4161 \mathrm{~g} / \mathrm{L} \\
\mathrm{C}_{\mathrm{C}}=0.5743 \mathrm{~g} / \mathrm{L} \\
\mathrm{Q}_{\mathrm{F}, \mathrm{TMB} 2}=0.2687 \mathrm{~mL} / \mathrm{min} \\
\mathrm{Q}_{1, \mathrm{TMB} 2}=2.714 \mathrm{~mL} / \mathrm{min}\end{array}$ & $\begin{array}{l}\mathrm{C}_{\mathrm{A}}=0.0065 \mathrm{~g} / \mathrm{L} \\
\mathrm{C}_{\mathrm{B}}=0.4414 \mathrm{~g} / \mathrm{L} \\
\mathrm{C}_{\mathrm{C}}=0.6379 \mathrm{~g} / \mathrm{L} \\
\mathrm{Q}_{\mathrm{F}, \mathrm{TMB} 2}=0.2790 \mathrm{~mL} / \mathrm{min} \\
\mathrm{Q}_{1, \mathrm{TMB} 2}=2.818 \mathrm{~mL} / \mathrm{min}\end{array}$ \\
\hline $\begin{array}{l}\text { Outlet of TMB2 } \\
\text { (Raffinate port) }\end{array}$ & & & $\begin{array}{l}\mathrm{C}_{\mathrm{B}}=1.0 \mathrm{~g} / \mathrm{L}, \\
\mathrm{Q}_{\mathrm{R}, \mathrm{TMB} 2}=0.25 \mathrm{~mL} / \mathrm{min}\end{array}$ & $\begin{array}{l}\mathrm{C}_{\mathrm{B}}=0.3674 \mathrm{~g} / \mathrm{L}, \\
\mathrm{C}_{\mathrm{A}}=0.00243 \mathrm{~g} / \mathrm{L}, \\
\mathrm{Q}_{\mathrm{R}, \mathrm{TMB} 2}=0.3044 \mathrm{~mL} / \mathrm{min}\end{array}$ & $\begin{array}{l}\mathrm{C}_{\mathrm{B}}=0.3896 \mathrm{~g} / \mathrm{L}, \\
\mathrm{C}_{\mathrm{A}}=0.00395 \mathrm{~g} / \mathrm{L}, \\
\mathrm{Q}_{\mathrm{R}, \mathrm{TMB} 2}=0.3161 \mathrm{~mL} / \mathrm{min}\end{array}$ \\
\hline $\begin{array}{l}\text { Desorbent for } \\
\text { TMB2 }\end{array}$ & & & $\mathrm{Q}_{\mathrm{D}, \mathrm{TMB} 2}=0.25 \mathrm{~mL} / \mathrm{min}$ & $\mathrm{Q}_{\mathrm{D}, \mathrm{TMB} 2}=0.3492 \mathrm{~mL} / \mathrm{min}$ & $\mathrm{Q}_{\mathrm{D}, \mathrm{TMB} 2}=0.3626 \mathrm{~mL} / \mathrm{min}$ \\
\hline $\begin{array}{l}\text { Total outlet mass } \\
\text { flux of target B }\end{array}$ & $2.000 * 10^{-2} \mathrm{~g} / \mathrm{h}$ & $1.414^{*} 10^{-3} \mathrm{~g} / \mathrm{h}$ & $3.000 * 10^{-2} \mathrm{~g} / \mathrm{h}$ & $1.340 * 10^{-2} \mathrm{~g} / \mathrm{h}$ & $1.475^{*} 10^{-2} \mathrm{~g} / \mathrm{h}$ \\
\hline Productivity $\operatorname{Pr}_{B}$ & $14.15 \mathrm{~g} / \mathrm{L} / \mathrm{h}$ & $1.001 \mathrm{~g} / \mathrm{L} / \mathrm{h}$ & $2.358 \mathrm{~g} / \mathrm{L} / \mathrm{h}$ & $1.050 \mathrm{~g} / \mathrm{L} / \mathrm{h}$ & $1.163 \mathrm{~g} / \mathrm{L} / \mathrm{h}$ \\
\hline Total yield $Y_{B}$ & $100 \%$ & $36.63 \%$ & $100 \%$ & $100 \%$ & $100 \%$ \\
\hline $\begin{array}{l}\text { Total eluent } \\
\text { flowrate } \\
\end{array}$ & $1 \mathrm{~mL} / \mathrm{min}$ & $1 \mathrm{~mL} / \mathrm{min}$ & $1.5 \mathrm{~mL} / \mathrm{min}$ & $1.711 \mathrm{~mL} / \mathrm{min}$ & $1.732 \mathrm{~mL} / \mathrm{min}$ \\
\hline $\begin{array}{l}\text { Specific eluent } \\
\text { consumption }\end{array}$ & $3.000 \mathrm{~L} / \mathrm{g}$ & $42.43 \mathrm{~L} / \mathrm{g}$ & $3.000 \mathrm{~L} / \mathrm{g}$ & $8.140 \mathrm{~L} / \mathrm{g}$ & $7.486 \mathrm{~L} / \mathrm{g}$ \\
\hline
\end{tabular}




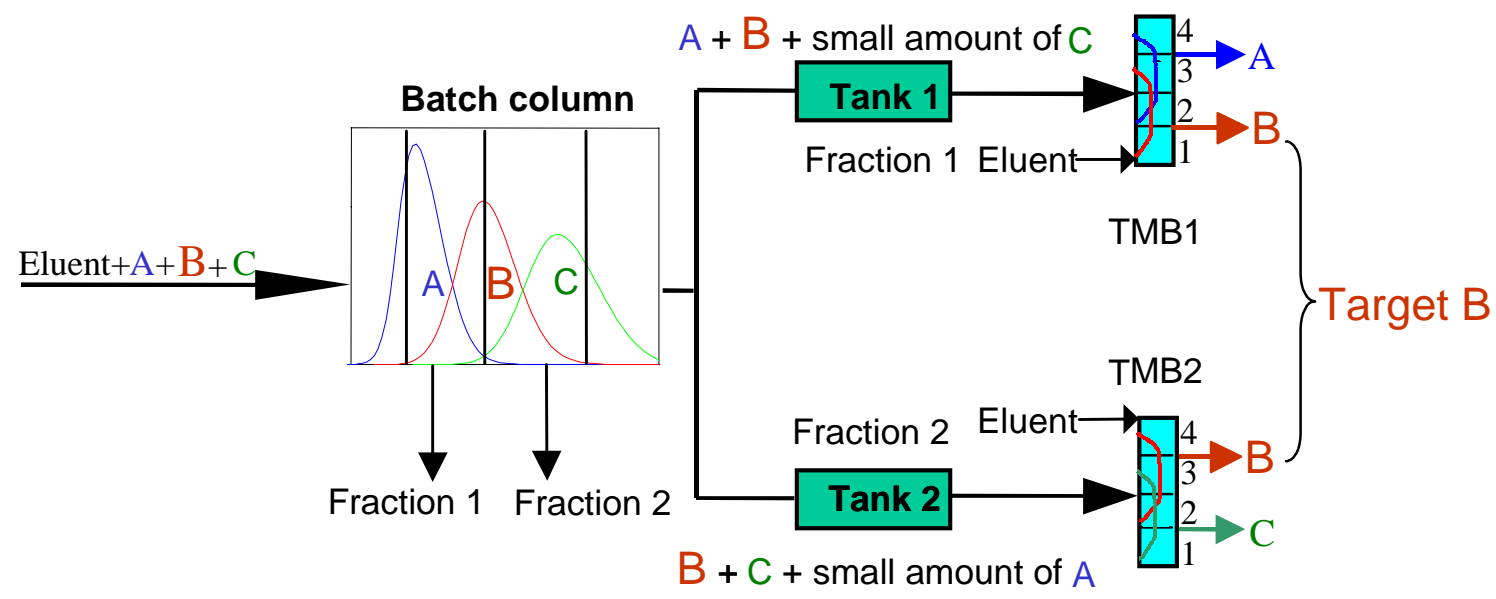

\section{Fig. 1:}

Schematic illustration of coupling batch elution chromatography and two countercurrent units in order to isolate the second component (B) from a ternary mixture (components $\mathrm{A}, \mathrm{B}$ and $\mathrm{C}$ ). 

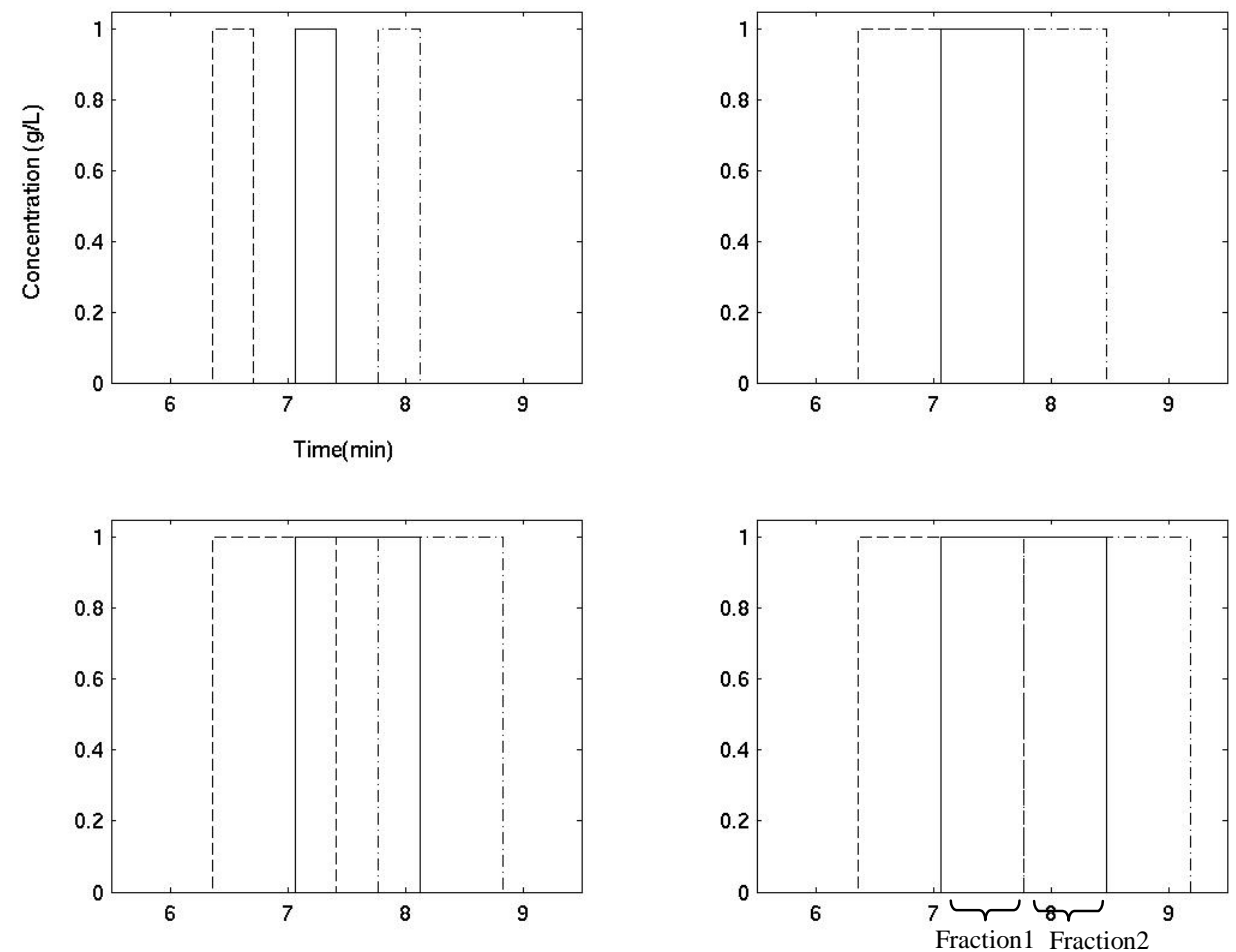

Fig. 2:

Chromatograms in batch column for constant injection concentrations $\left(\mathrm{C}_{\mathrm{inj}, \mathrm{A}}=\mathrm{C}_{\mathrm{inj}, \mathrm{B}}=\mathrm{C}_{\mathrm{inj}, \mathrm{C}}=1.0 \mathrm{~g} / \mathrm{L}\right)$ but different injection volumes as predicted by the ideal model: (a) $\mathrm{V}_{\text {inj }}=0.353 \mathrm{~mL}$; (b) $0.707 \mathrm{~mL}$; (c) $1.061 \mathrm{~mL}$; (d) $1.413 \mathrm{~mL}$ 


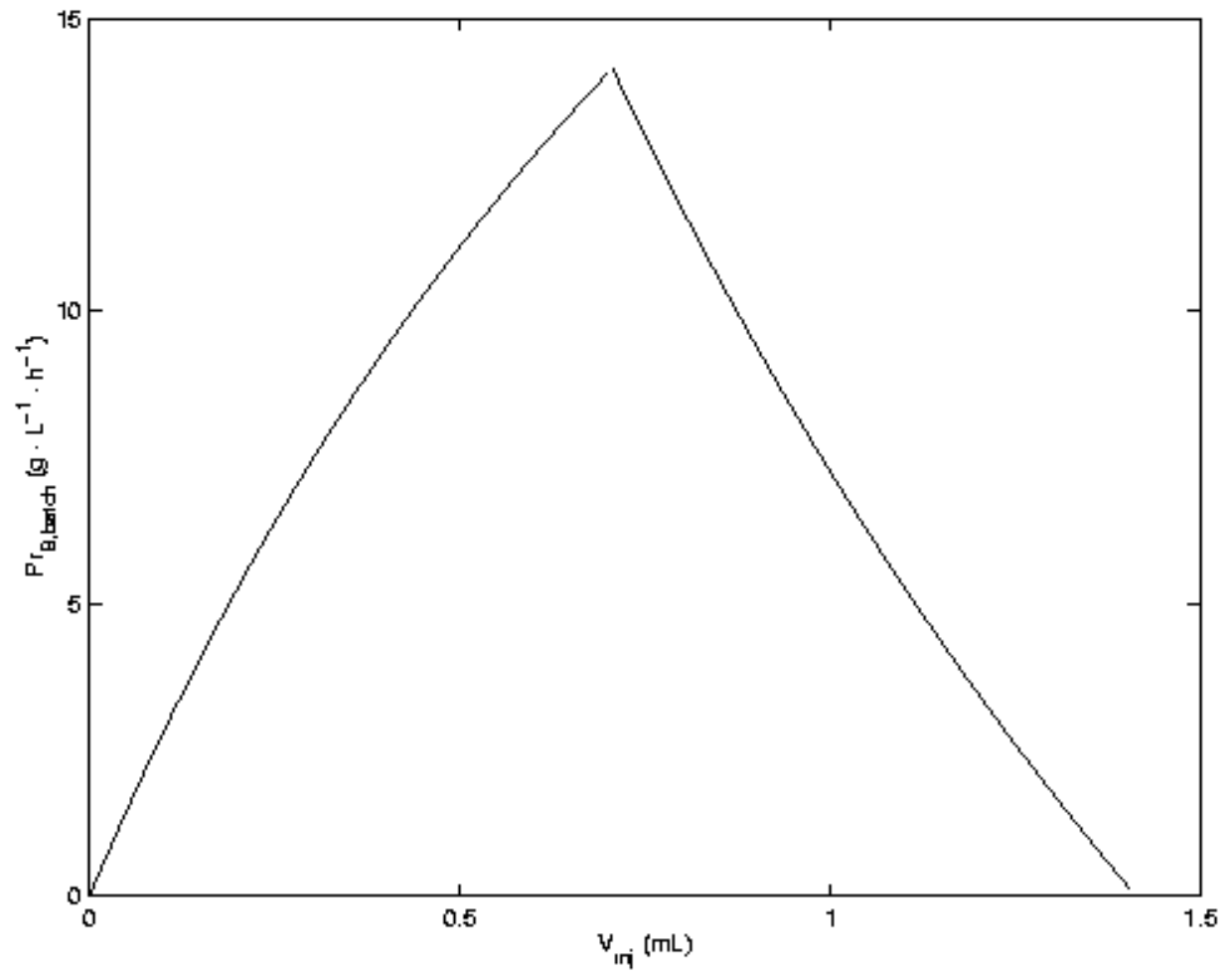

Fig. 3:

Relationship between the productivity of producing the target component B and the injection volume (ideal batch chromatography. 

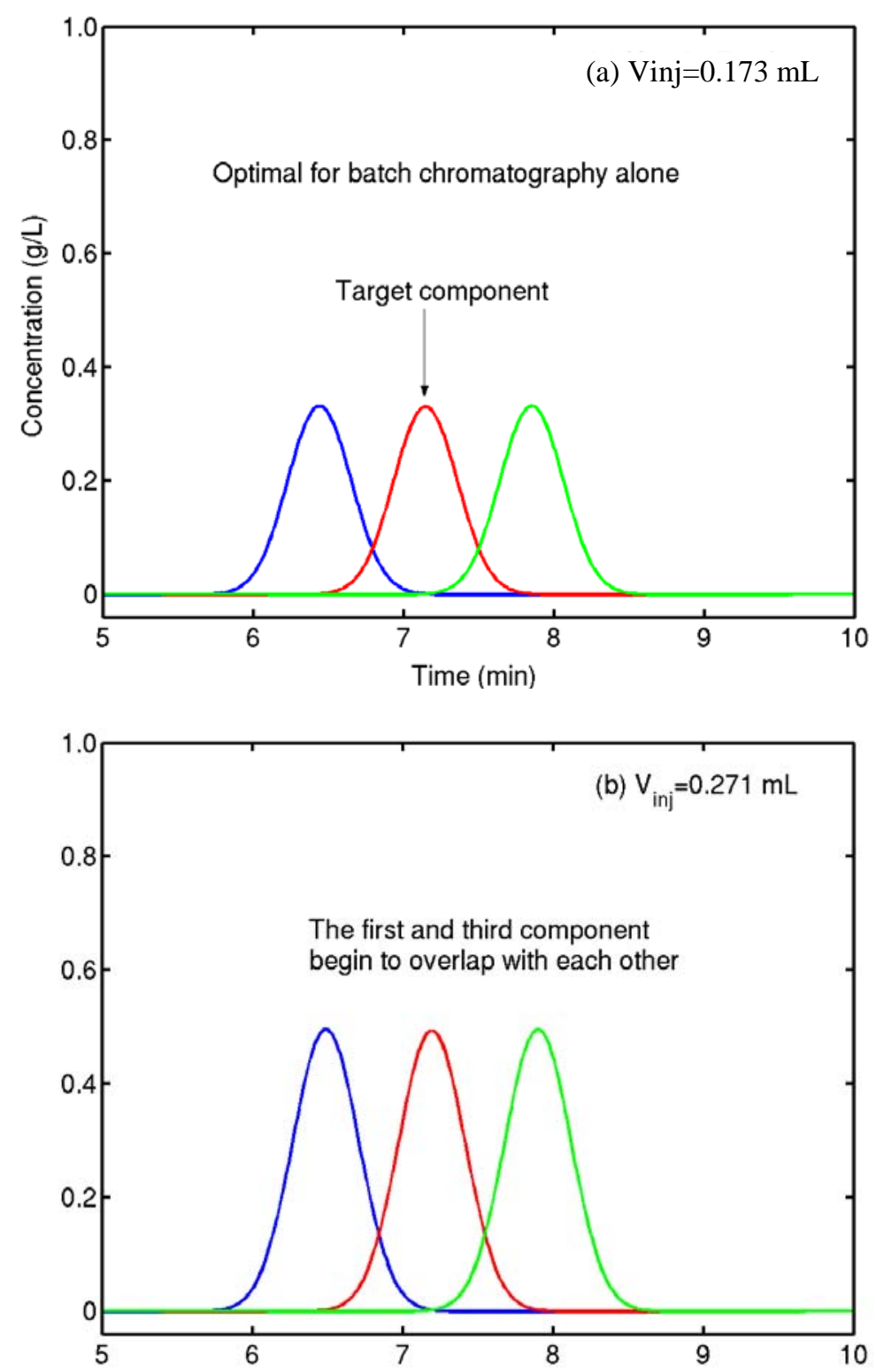

Fig. 4:

Elution profiles of batch chromatography predicted by the equilibrium dispersive (nonideal, $\mathrm{N}_{\mathrm{P}}=1200$ ) model for two different injection volumes. 


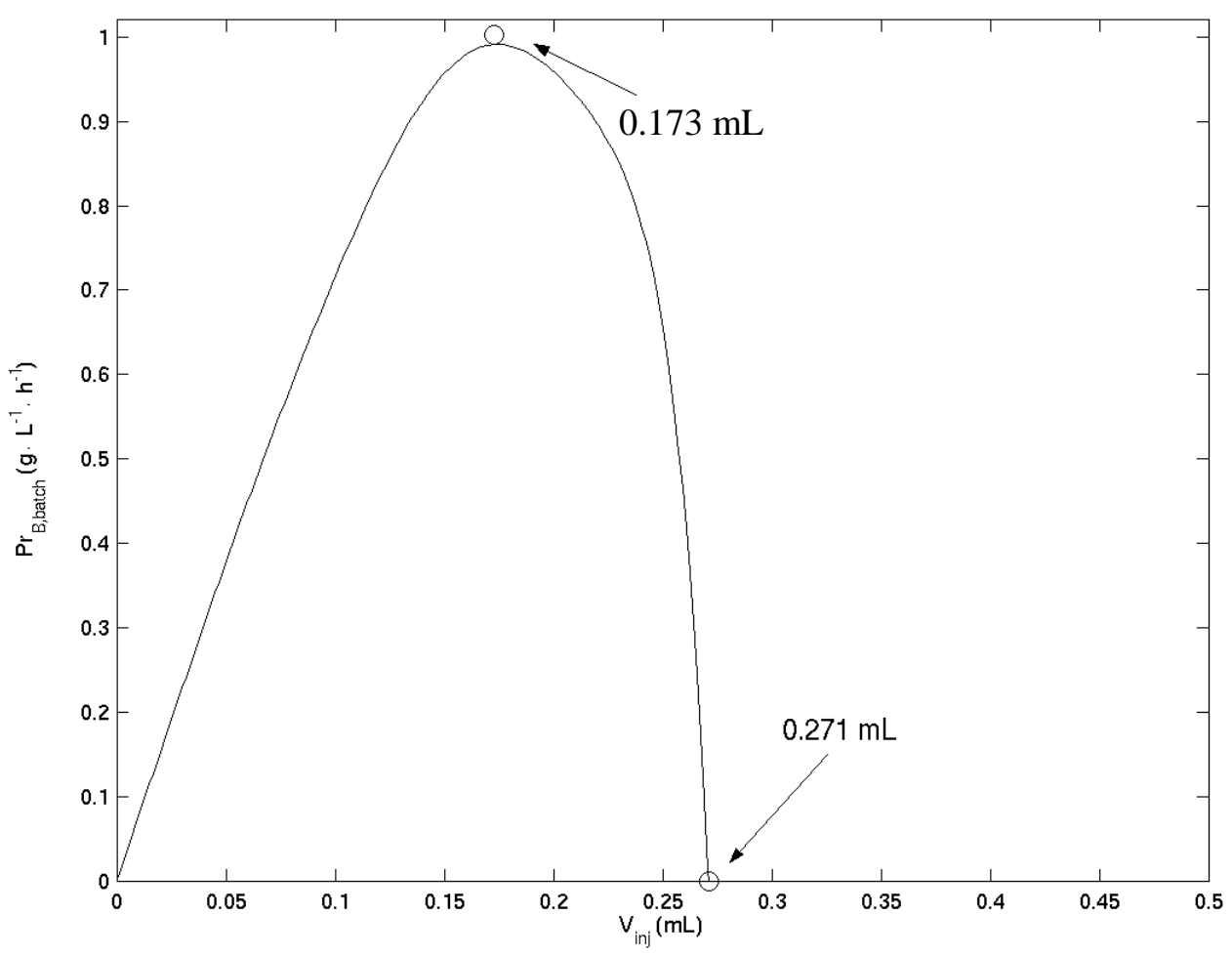

Fig. 5:

Relationship between the productivity of producing the target component B and the injection volume (nonideal batch chromatography, $N_{P}=1200$ ). 


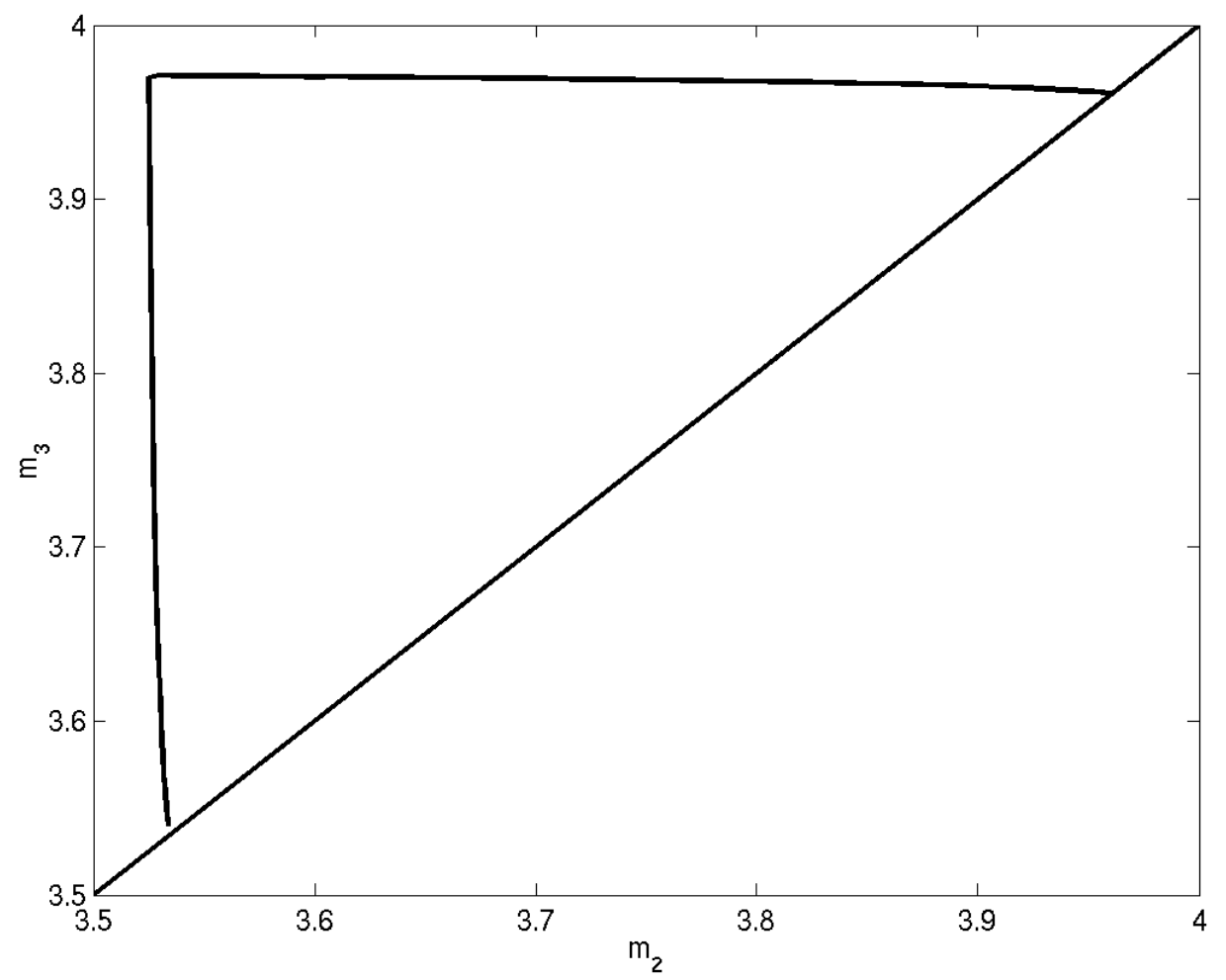

Fig. 6:

The region of complete separation for components $\mathrm{A}$ and $\mathrm{B}$ as predicted by the nonideal model $\left(\mathrm{N}_{\mathrm{P}}=1200\right)$ for TMB1 $\left(\mathrm{m}_{1}=\beta \cdot \mathrm{H}_{\mathrm{B}}, \mathrm{m}_{4}=\mathrm{H}_{\mathrm{A}} / \beta, \beta=1.01\right)$. 


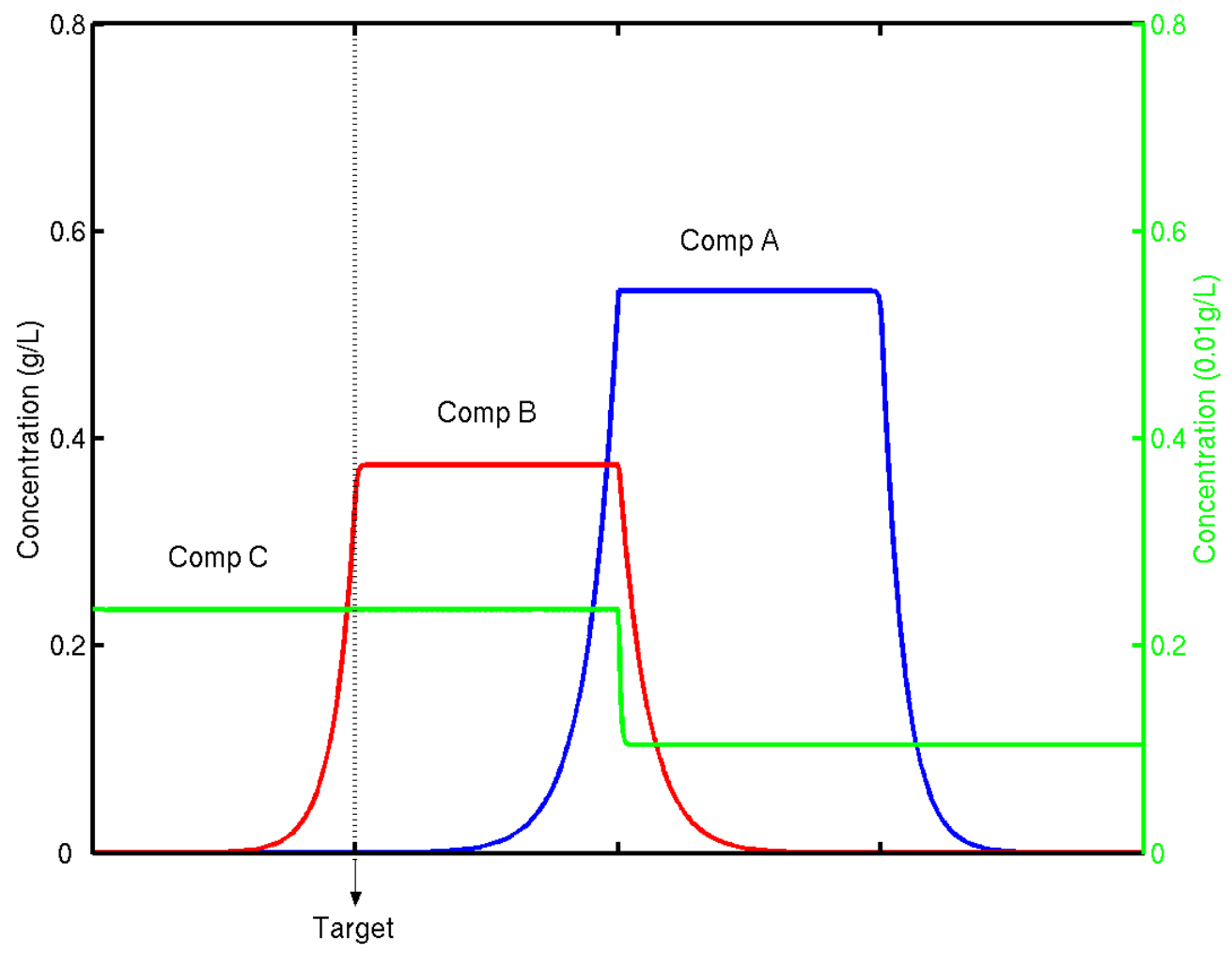

Fig. 7:

The internal concentration profile in TMB1 of the three components being in Fraction 1 for the following operating conditions: $V_{\text {inj,batch }}=0.706 \mathrm{~mL}, \mathrm{~m}_{1}: \mathrm{m}_{2}: \mathrm{m}_{3}: \mathrm{m}_{4}=4.04$ : 3.525: 3.970: $3.465, \mathrm{~N}_{\mathrm{P}}=1200$. The resulting outlet concentrations at the extract port are: $C_{A}: C_{B}: C_{C}=0.000: 0.3454: 0.0023$ g/L, i.e. Pur $_{B, d e s}=99.32 \%>99 \%$. 

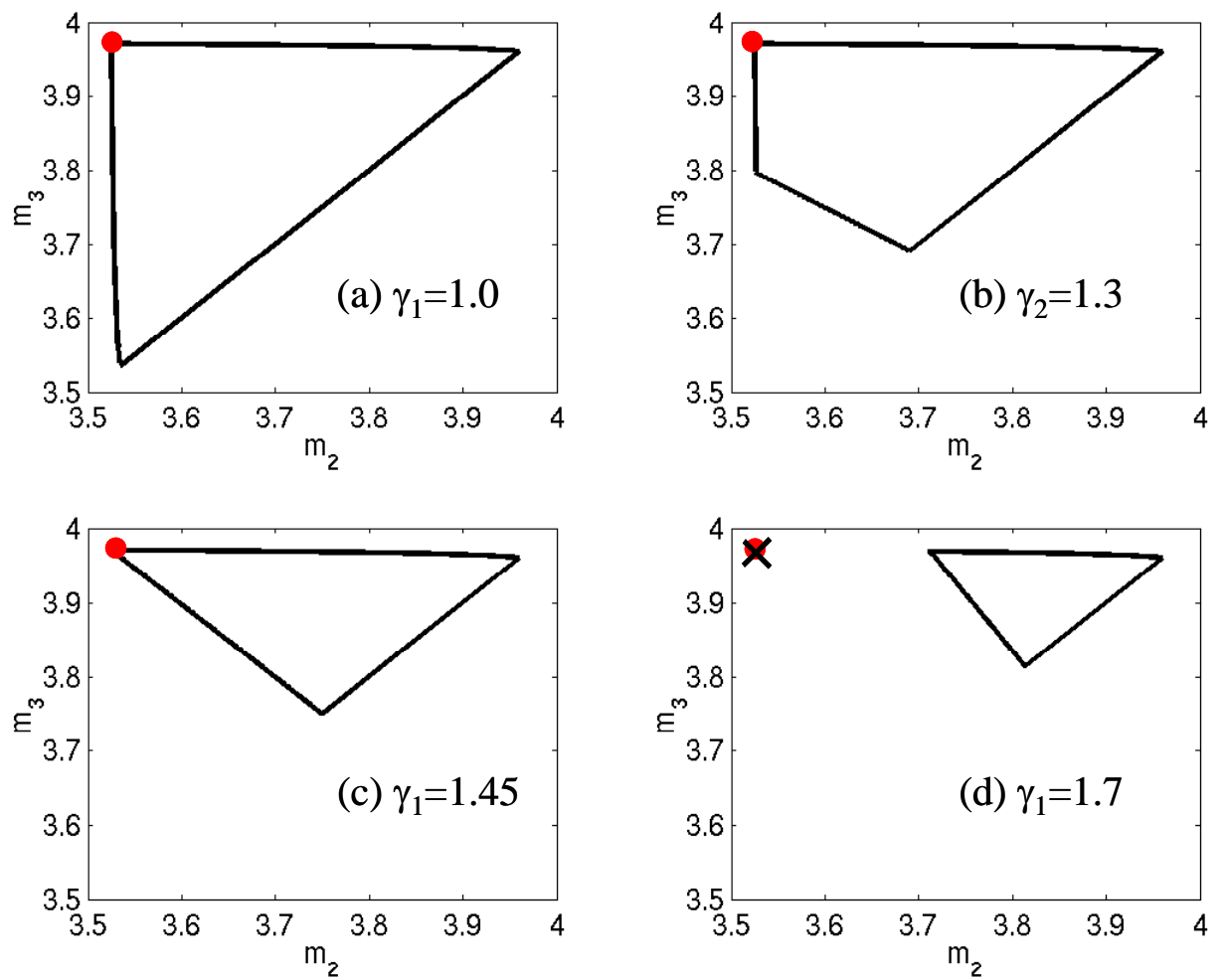

Fig. 8:

Effect of the amount of minor impurity (e. g. component $\mathrm{C}$ in Fraction 1 entering TMB1) on the size of the region of complete separation $\left(\operatorname{Pur}_{B, d e s}=99 \%, N_{P}=1200\right.$ ). The separation region in Fig. 8a is the same as shown in Fig. 6. 


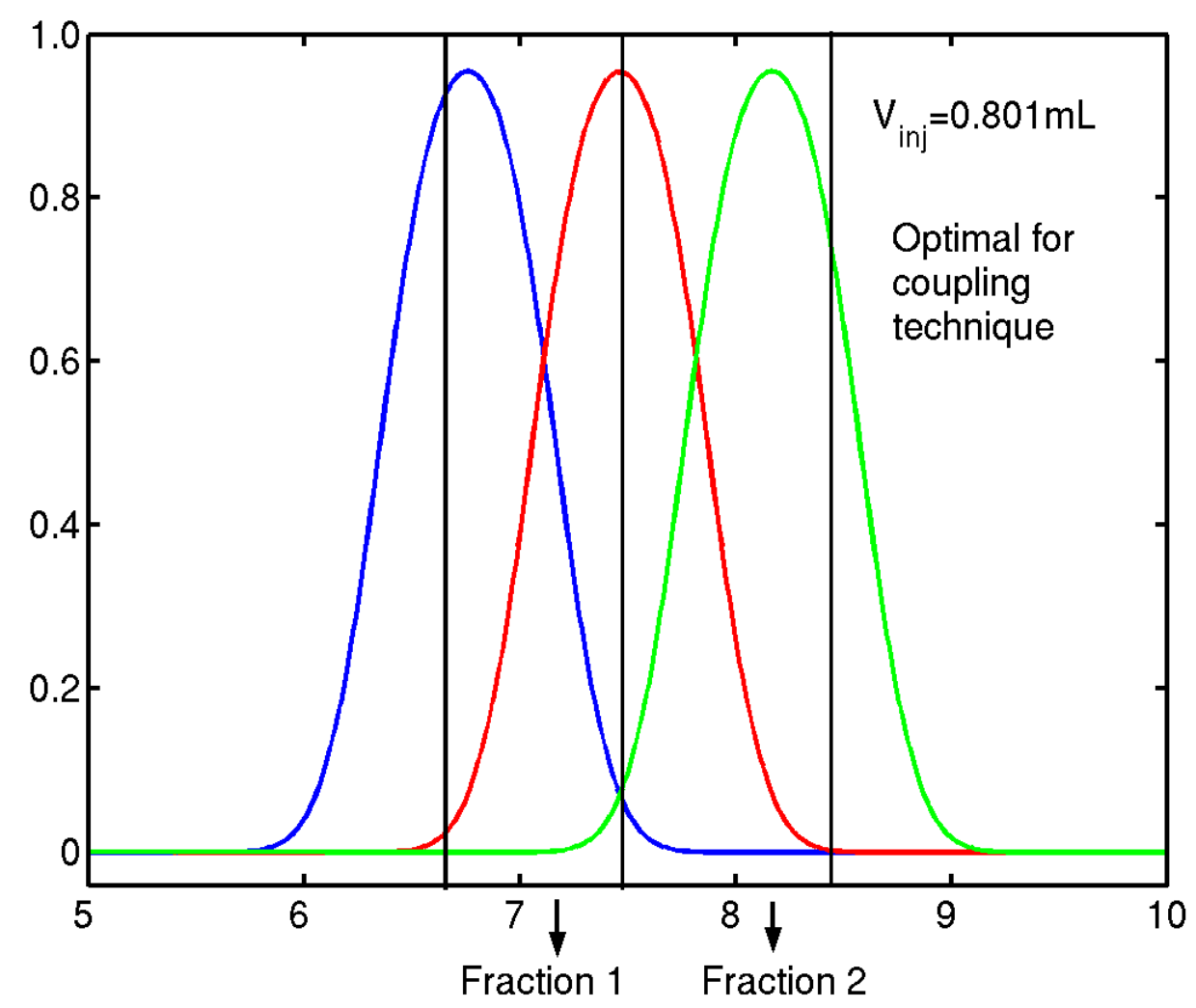

Fig. 9:

Elution chromatogram of the batch column corresponding to the optimal injection volume of the coupled process as predicted by the equilibrium dispersive (nonideal) model. 


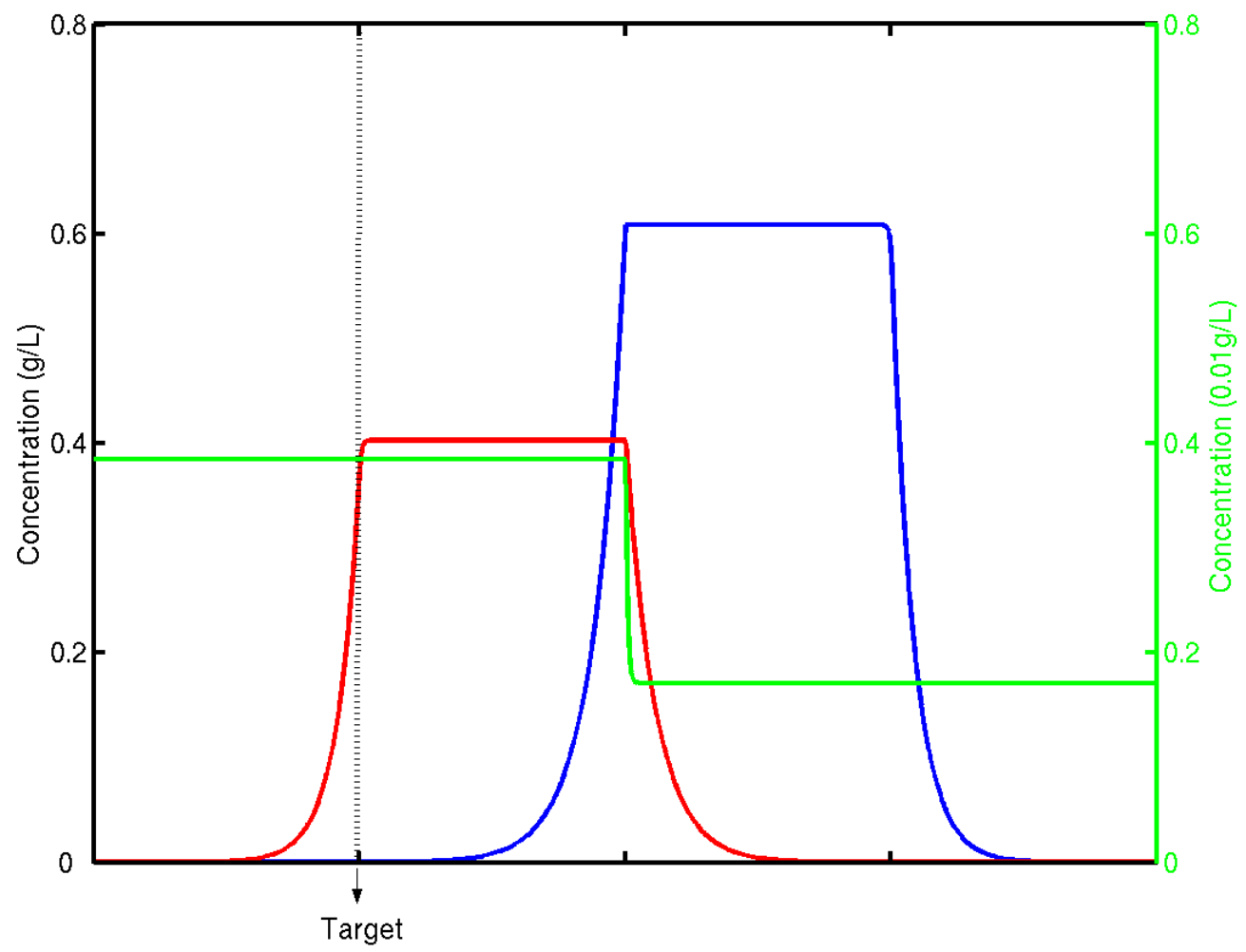

Fig. 10:

The internal concentration profile in TMB1 of the three components being in Fraction 1 for the following operation conditions:, $V_{\text {inj,batch }}=0.801 \mathrm{~mL}, \mathrm{~m}_{1}: \mathrm{m}_{2}: \mathrm{m}_{3}: \mathrm{m}_{4}=4.04$ : 3.525: 3.970: $3.465, \mathrm{~N}_{\mathrm{P}}=1200$. The resulting outlet concentrations at the extract port are: $\mathrm{C}_{\mathrm{A}}: \mathrm{C}_{\mathrm{B}}: \mathrm{C}_{\mathrm{C}}=0.0000: 0.3716: 0.00385 \mathrm{~g} / \mathrm{L}$, i.e. Pur $_{\mathrm{B}, \mathrm{des}}=99 \%$. 


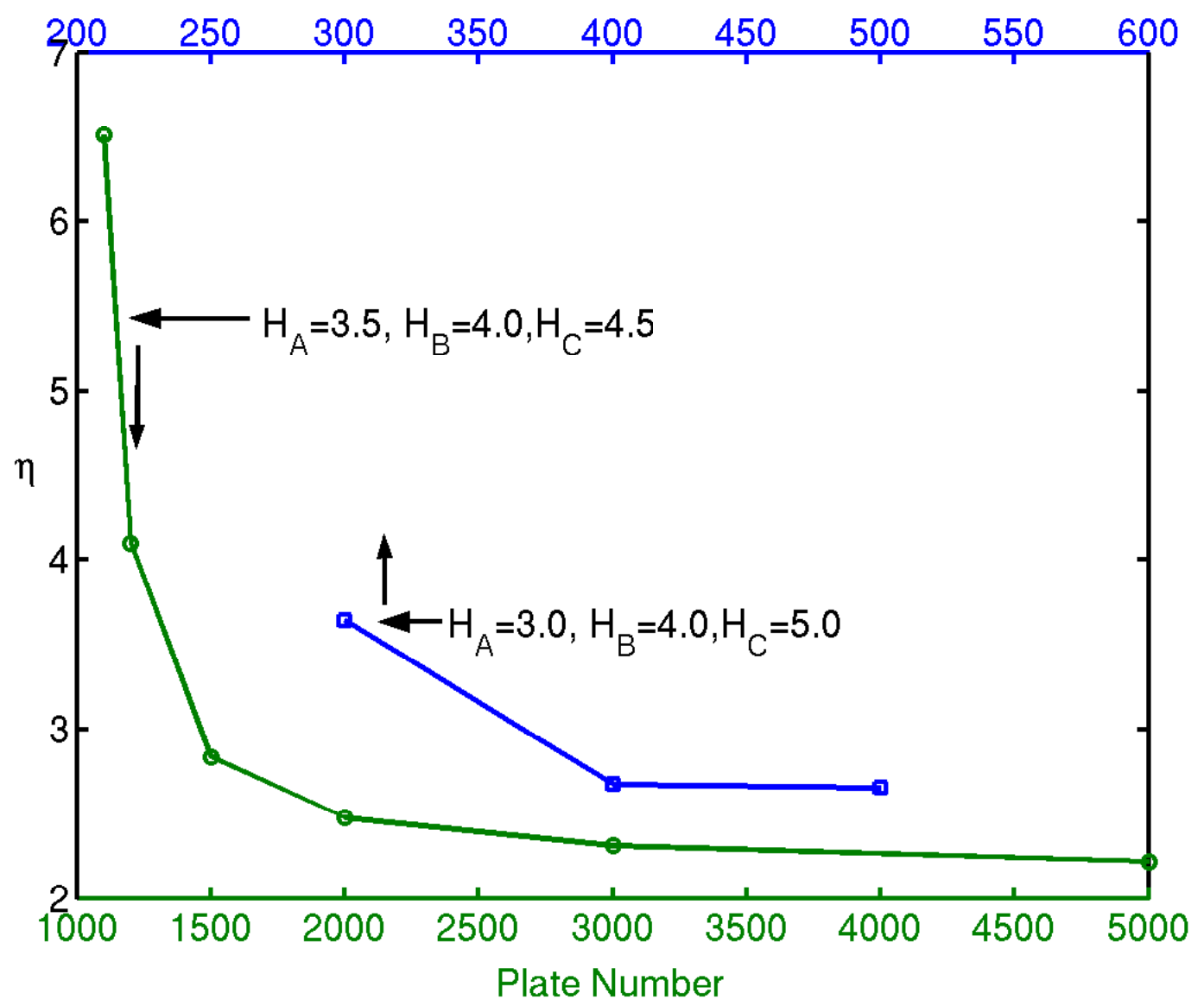


Fig. 11:

Effect of a variation of the isotherm parameters $\mathrm{H}_{\mathrm{A}}$ and $\mathrm{H}_{\mathrm{B}}$ and plate number $\mathrm{N}_{\mathrm{P}}$ on the value of $\eta$ (eq. 24) for the nonideal case and $\operatorname{Pur}_{\mathrm{B}, \mathrm{des}}=99 \%$. 